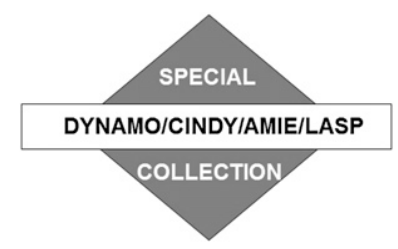

\title{
Tropospheric Turbulence over the Tropical Open Ocean: Role of Gravity Waves
}

\author{
H. Bellenger, ${ }^{a}$ R. Wilson, ${ }^{\mathrm{b}}$ J. L. Davison, ${ }^{\mathrm{c}}$ J. P. Duvel, ${ }^{\mathrm{d}}$ W. Xu, ${ }^{\mathrm{e}}$ F. LotT, ${ }^{\mathrm{d}}$ And M. KAtsumatA ${ }^{\mathrm{a}}$ \\ ${ }^{a}$ Japan Agency for Marine-Earth Science and Technology, Yokosuka, Japan \\ ${ }^{\mathrm{b}}$ Laboratoire Atmosphere, Milieux, Observations Spatiales, Paris, France \\ ${ }^{\mathrm{c}}$ Lower Atmosphere Research Group, Merritt Island, Florida \\ ${ }^{\mathrm{d}}$ Laboratoire de Météorologie Dynamique, Paris, France \\ ${ }^{\mathrm{e}}$ Department of Atmospheric Science, Colorado State University, Fort Collins, Colorado
}

(Manuscript received 3 May 2016, in final form 31 October 2016)

\begin{abstract}
A large set of soundings obtained in the Indian Ocean during three field campaigns is used to provide statistical characteristics of tropospheric turbulence and its link with gravity wave (GW) activity. The Thorpe method is used to diagnose turbulent regions of a few hundred meters depth. Above the mixed layer, turbulence frequency varies from $\sim 10 \%$ in the lower troposphere up to $\sim 30 \%$ around 12 -km height. GWs are captured by their signature in horizontal wind, normalized temperature, and balloon vertical ascent rate. These parameters emphasize different parts of the wave spectrum from longer to shorter vertical wavelengths. Composites are constructed in order to reveal the vertical structure of the waves and their link with turbulence. The relatively longer-wavelength GWs described by their signature in temperature (GWTs) are more active in the lower troposphere, where they are associated with clear variations in moisture. Turbulence is then associated with minimum static stability and vertical shear, stressing the importance of the former and the possibility of convective instability. Conversely, the short waves described by their signature in balloon ascent rate ( $\mathrm{GWws}$ ) are detected primarily in the upper troposphere, and their turbulence is associated with a vertical shear maximum, suggesting the importance of dynamic instability. Furthermore, GWws appear to be linked with local convection, whereas GWTs are more active in suppressed and dry phases in particular of the Madden-Julian oscillation. These waves may be associated with remote sources, such as organized convection or local fronts, such as those associated with dry-air intrusions.
\end{abstract}

\section{Introduction}

To correctly represent Earth's climate, it is imperative to understand and quantify the processes that play a role in water vapor variability. The nonlinear relationship between free-tropospheric moisture and outgoing longwave radiation at the top of the atmosphere (e.g., Spencer and Braswell 1997) is a wellknown example of the importance of these processes for global climate. In addition, the characteristics of tropical moist convection strongly depend on the tropospheric moisture (e.g., Jensen and Del Genio 2006; Holloway and Neelin 2009; Takemi 2015), and so too does the convection's ability to organize on a large scale in the Madden-Julian oscillation (MJO) convective

Corresponding author e-mail: Hugo Bellenger, hbellenger@ jamstec.go.jp phase (e.g., Johnson et al. 2001; Benedict and Randall 2007). In 2011/12, an international campaign, the Cooperative Indian Ocean Experiment on Intraseasonal Variability/Dynamics of the MJO [CINDY/DYNAMO, hereafter C/D (Yoneyama et al. 2013)], was conducted in the equatorial Indian Ocean in order to study the triggering and the early evolution of the MJO. An early fundamental finding from this campaign is the very large variation in relative humidity $(\mathrm{RH})$ within the free troposphere that is commonly observed in the heart of the intertropical convergence zone (ITCZ): namely, extremely dry tropospheric regions $(\mathrm{RH}<$ $10 \%)$ near (in space and time) very humid ones ( $\mathrm{RH}>$ $90 \%$ ) between the 700- and 300-hPa levels (Yoneyama et al. 2013, their Fig. 9). The moisture perturbations show large diversity in spatial and temporal scales. The MJO organizes intraseasonal moisture perturbations at the Indian Ocean Basin scale. At finer scales, dry-air 


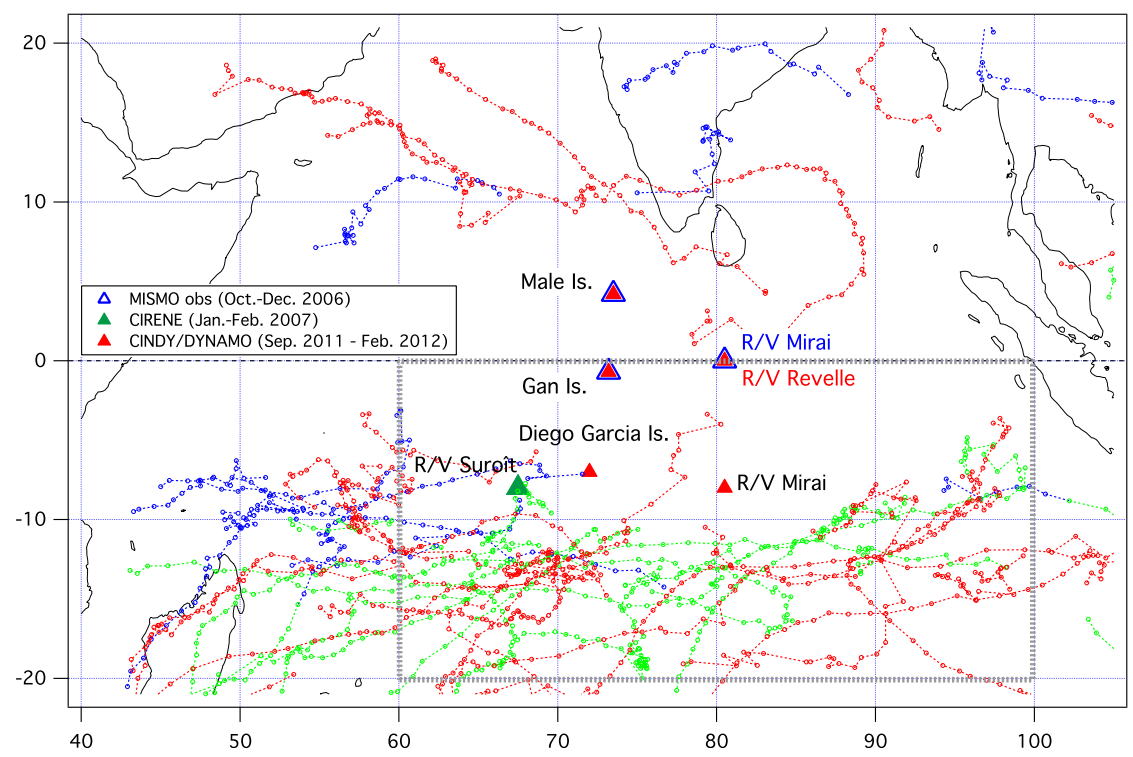

FIG. 1. Locations of the observation sites and research vessels stations (triangles) for the MISMO (blue), CIRENE (green), and C/D (red) experiments. Positions and tracks of vortices (Duvel 2015) that formed during the different experiments are indicated by the correspondingly colored dotted paths (see section $2 \mathrm{~d}$ for details). Details on the number and frequencies of launches together with the type of radiosondes are given in Table 1.

intrusions also strongly modulate tropospheric moisture (Redelsperger et al. 2002). Examples of these dry intrusions were observed during $\mathrm{C} / \mathrm{D}$ (Kerns and Chen 2014). Bellenger et al. (2015a) showed anomalies of specific humidity at the scale of individual clouds and their effect on the mesoscale moisture field. Finally, finescale sheets and layered structures of a few hundred meters depth can be detected in the moisture field in the lower free troposphere (Luce et al. 2010a) and in particular over tropical oceans, where they may be associated with turbulence and cloud detrainment (Davison et al. 2013a,b,c; Davison 2015).

The multiscale nature of moisture variability reflects the diversity of processes involved. This makes the tropospheric moisture budget particularly difficult to close even on the large scale. Indeed, the moisture tendencies computed over regions of the size of C/D sounding arrays (Fig. 1) are usually found to be smaller than or on the same order of magnitude as the other moisture budget terms (e.g., Ruppert and Johnson 2015). This is particularly true for tendencies associated with convective processes (Waite and Khouider 2010; Bellenger et al. 2015a; Ruppert and Johnson 2015; Zermeño-Díaz et al. 2015; Powell and Houze 2015; Takemi 2015). In addition, Bellenger et al. (2015b) suggested that the usually neglected freetropospheric clear-air turbulent mixing might also play some role in vertical moisture transport in the presence of steep vertical gradients of moisture above the boundary layer as observed during the suppressed phase of the MJO or in conjunction with dry intrusions.

In the cloud-free free atmosphere, turbulence occurs intermittently in the form of isolated and horizontally elongated patches (e.g., Wilson et al. 2005). The resulting effects of these intense and localized mixing events are difficult to evaluate (Dewan 1981; Woodman and Rastogi 1984; Vanneste and Haynes 2000), and evaluation of these effects is strongly sensitive to hypothesis choice and parameters that are hard to constrain experimentally [see the discussion in Bellenger et al. (2015b) and below]. Turbulence is usually detected using observations by high-power mesospherestratosphere-troposphere (MST) radars (e.g., Wilson 2004). The large size of their antenna array precludes their installation onboard research vessels, and alternative techniques have to be used to diagnose turbulence over oceanic regions.

The Thorpe technique (Thorpe 1977), which was originally developed to detect overturning in the ocean, was first used to detect atmospheric turbulence by Luce et al. (2002) using high-resolution soundings. Later, Clayson and Kantha (2008) popularized this technique by suggesting that it could enable the retrieval of turbulence characteristics from operational radiosondes measurements, although the turbulence detection is then limited to the largest turbulent patches (Wilson et al. 2011). In addition, special care has to be taken in the treatment of instrumental-noise-induced false signal 
(Wilson et al. 2010, hereafter W10). Several subsequent studies used meteorological soundings to assess the turbulence in the troposphere and the stratosphere (Nath et al. 2010; Alappattu and Kunhikrishnan 2010; Liu et al. 2014; Bellenger et al. 2015b). However, only the latter followed the methodology developed by W10 to properly treat the instrumental-noise issue.

Turbulence can originate from static instabilities or from Kelvin-Helmholtz instabilities. These instabilities can be associated with gravity wave (GW) activity (Cadet 1977; Barat 1983; Chao and Schoeberl 1984; Fritts and Dunkerton 1985; Fritts and Rastogi 1985; Fritts et al. 1988b; Pavelin et al. 2001; Sharman et al. 2012; Fritts et al. 2016). This suggests the possibility of GWs playing a role in the formation of the layered $\mathrm{RH}$ structure that can be observed in the lower troposphere (Luce et al. 2010a; Davison et al. 2013c; Fritts et al. 2016). It was also suggested that turbulence can originate from the reduced static stability inside clouds (Wilson et al. 2013; Worthington 2015) or be triggered by the evaporative cooling under cloud layers (Luce et al. 2010c; Wilson et al. 2014). Unlike turbulence, the analysis of GWs in radiosonde profiles has a long history (Cadet 1977; Barat 1983, Tsuda et al. 1994a,b; Karoly et al. 1996; Shimizu and Tsuda 1997; Reeder et al. 1999; Sato et al. 2003; Lane et al. 2003; Geller and Gong 2010; Gong and Geller 2010; Ki and Chun 2010; Suzuki et al. 2013; Hankinson et al. 2014a,b). In particular, it has been shown that perturbations in horizontal wind, temperature, and ascent rate from radiosondes can be used to depict different parts of the GW spectrum (Lane et al. 2003; Geller and Gong 2010). Shorter-wavelength/ higher-frequency waves are likely to be observed close to their source, whereas longer-wavelength/ lower-frequency GWs can propagate great distance away from their sources (e.g., Hankinson et al. 2014a, b). Over the central equatorial Indian Ocean, which lacks any significant orography, the most probable GW sources are convection and jet streams. Therefore, we anticipate an observable link between convective activity (both local and distant), GW characteristics, and turbulence.

This study is based on radiosonde observations collected during central tropical Indian Ocean field experiments. In section 2 , we discuss the specific datasets and the methods used to diagnose turbulence and GWs and introduce several indices used to depict weather variability in the tropical Indian Ocean. We then derive statistics of tropospheric turbulence in a tropical openocean region (section 3 ) and study the relationship between turbulence and GW activity (section 4). In section 5, the relationships between turbulence variability and synoptic and intraseasonal atmospheric phenomena are explored. A discussion and conclusions are provided in section 6 .

\section{Data and method}

\section{a. Observation data}

We use 3523 Vaisala RS92-SGPD soundings that were taken near the equatorial central Indian Ocean during three field campaigns: the Mirai Indian Ocean Cruise for the Study of the MJO-Convection Onset (MISMO) campaign that took place in October-December 2006 (Yoneyama et al. 2008), the CIRENE cruise part of the Validation of the Aeroclipper System under Convective Occurrence (VASCO)-CIRENE campaign that took place during January-February 2007 (Vialard 2007; Vialard et al. 2009; Duvel et al. 2009) and C/D that took place from September 2011 to February 2012 (Yoneyama et al. 2013). The map on Fig. 1 shows the observing sites for these three campaigns.

MISMO and CIRENE occurred during a weak El Niño event and following a positive Indian Ocean dipole (Vialard 2007; Vialard et al. 2009). In contrast, C/D took place in La Niña conditions, which in the Indian Ocean are more favorable for the occurrence of intraseasonal convective events associated with the MJO (Bellenger and Duvel 2012). MISMO captured the developing stage of an MJO-like intraseasonal perturbation, which did not propagate farther than the Maritime Continent (Yoneyama et al. 2008, their Fig. 5). During CIRENE, convection and MJO activity were weak over the Indian Ocean and primarily located over the Maritime Continent and the Pacific Ocean. Conditions at the Research Vessel (R/V) Suroit were largely suppressed, with the exceptions of the end of the first leg and the beginning of the second leg, when convection was active in association with Tropical Cyclone Dora.

During $\mathrm{C} / \mathrm{D}$, equatorial and Northern Hemisphere sites (Gan, Male, and R/V Revelle) contrasted strongly with the Southern Hemisphere sites [Diego Garcia and R/V Mirai (see Yoneyama et al. 2013; Ciesielski et al. 2014)]. On the equator and farther north, three distinct MJO events were captured with clear transitions from dry and suppressed phase to developing convection, followed by a deep convective phase and then decay (Powell and Houze 2013; Zuluaga and Houze 2013; Rowe and Houze 2014; Xu and Rutledge 2014; Xu et al. 2015). R/V Mirai mainly experienced shallow convective situations (Yoneyama et al. 2013; Bellenger et al. 2015a; Xu et al. 2015) with some short-lived deep convective occurrences associated with a migration of the ITCZ. These deep convective events corresponded to ITCZ convective activity. The disruption of the ITCZ 
TABLE 1. Site-by-site basic characteristics of the soundings used in this study (see text for details).

\begin{tabular}{lcclc}
\hline \hline & $\begin{array}{c}\text { Number of } \\
\text { soundings }\end{array}$ & $\begin{array}{c}\text { Sounding } \\
\text { frequency }\left(\text { day }^{-1}\right)\end{array}$ & \multicolumn{1}{c}{ Observation dates } & $\begin{array}{c}\text { Bulk trend-to-noise } \\
\text { ratio }\end{array}$ \\
\hline MISMO Gan & 205 & $2-4$ & 22 Sep-31 Dec 2006 & 2.1 \\
MISMO Male & 76 & $2-4$ & 24 Oct-25 Nov 2006 & 2.2 \\
MISMO R/V Mirai & 284 & $4-8$ & 23 Oct-1 Dec 2006 & 2 \\
CIRENE & 102 & $4-8$ & 14-24 Jan and 4-16 Feb 2007 & 1.8 \\
C/D Diego Garcia & 541 & $4-8$ & 30 Sep-15 Dec 2011 & 1.8 \\
C/D Gan & 1043 & $4-8$ & 24-28 Sep and 1 Oct 2011-9 Feb 2012 & 2 \\
C/D Male & 323 & 4 & 29 Sep-15 Dec 2011 & 2 \\
C/D R/V Mirai & 489 & $4-8$ & 28 Sep-26 Oct and 29 Oct-1 Dec 2011 & 1.9 \\
C/D R/V Revelle & 460 & $4-8$ & 3-29 Oct, 10 Nov-4 Dec, and 18-31 Dec 2011 & 1.9 \\
\hline
\end{tabular}

during the three C/D MJO events induced an out-ofphase relationship between convection at R/V Mirai's position and the northern array. At Diego Garcia, shortlived convective events were more frequent than at R/V Mirai's position, but no clear organization on the intraseasonal time scale is evident (e.g., Yoneyama et al. 2013, their Fig. 9). Dry intrusions are detectable in the data from Gan, Diego Garcia, and R/V Mirai, some of which have been noted by Kerns and Chen (2014) (between 30 November-1 December for Gan and 21-24 November for Diego Garcia and R/V Mirai).

To characterize turbulence over open ocean (i.e., with minimal land influence), we concentrate on observations obtained from ships and from very small and flat atoll islands. We also limit the ship dataset to stationary periods for simplicity (this impacts only marginally the number of soundings that are used). Table 1 summarizes observation characteristics for each observing site: namely, the number of soundings, their launch frequency, and the observation periods. During $C / D$, the sounding frequency is generally 3 hourly.

C-band meteorological radars were utilized on $\mathrm{R} / \mathrm{V}$ Mirai during MISMO and on Gan Island, R/V Mirai, and R/V Revelle during C/D (details in Katsumata et al. 2008; Xu and Rutledge 2014; Feng et al. 2014). For these sites, it is thus possible to characterize the surrounding cloud population. This is simply done by considering the average echo-top height. During MISMO, echo tops were defined by a reflectivity threshold of $15 \mathrm{dBZ}$ (Yoneyama et al. 2008), whereas a threshold of $0 \mathrm{dBZ}$ is used for the three C/D C-band radars (Xu et al. 2015). Thus, for the sake of simplicity, we limit our comparison between radar-derived cloud population statistics and radiosonde-determined turbulence and $\mathrm{GW}$ events to the $\mathrm{C} / \mathrm{D}$ campaign.

\section{b. Clear-air turbulence diagnostic: Thorpe analysis}

Thorpe (1977) designed a simple method to characterize turbulence-induced overturns in the water by comparing the observed raw potential density profile to the corresponding stable profile obtained by reordering the water parcels in the vertical. The vertical displacements of the parcels from the reordering procedure are used to compute the Thorpe length scale $L_{T}$, which offers a characterization of the turbulence responsible for the observed overturn. Recently, the Thorpe analysis has been used to characterize atmospheric turbulence from radiosondes potential temperature $\theta$ profiles (Luce et al. 2002; Gavrilov et al. 2005; Clayson and Kantha 2008; Balsley et al. 2010; W10). For instance, Luce et al. (2002, 2014) and Wilson et al. (2014) used radar measurements to verify that the Thorpe analysis can be used to detect active turbulence in the atmosphere. We note, however, that the Thorpe analysis detects turbulent regions regardless of the physical origin of the instabilities (Kelvin-Helmoltz or convective instabilities).

W10 proposes a rigorous approach to reject spurious overturns created by instrumental noise, which we briefly describe here. The first step of this approach is to interpolate the sounding observations to a regular vertical grid. Figure 2a shows the mean vertical resolution for each campaign (and its variability with height). Except for Diego Garcia and R/V Revelle soundings with 1-s data, the other soundings have a time resolution of $2 \mathrm{~s}$. This corresponds to a vertical resolution of about 6-10 $\mathrm{m}$. Thus, we choose to interpolate the raw data to a regular 7-m grid. For each profile, the instrumentalnoise variance $\sigma_{N^{2}}$ is then diagnosed as the half of the variance of the data on 200-m segments from which a trend line is removed (W10). Figure $2 \mathrm{~b}$ shows the average profiles of the standard deviation of the instrumental noise induced on potential temperature data. The noise level tends to increase above the tropopause transition layer (13-14-km heights); we thus limit our analysis to the troposphere below $15 \mathrm{~km}$. This instrumental noise is first used to compute the bulk trendto-noise ratio (tnr) that is used to determine the optimal vertical resolution to be used for the Thorpe analysis (W10). The bulk tnr is typically expected to be between 1 and 3. If it is smaller, a denoising procedure (smoothing 

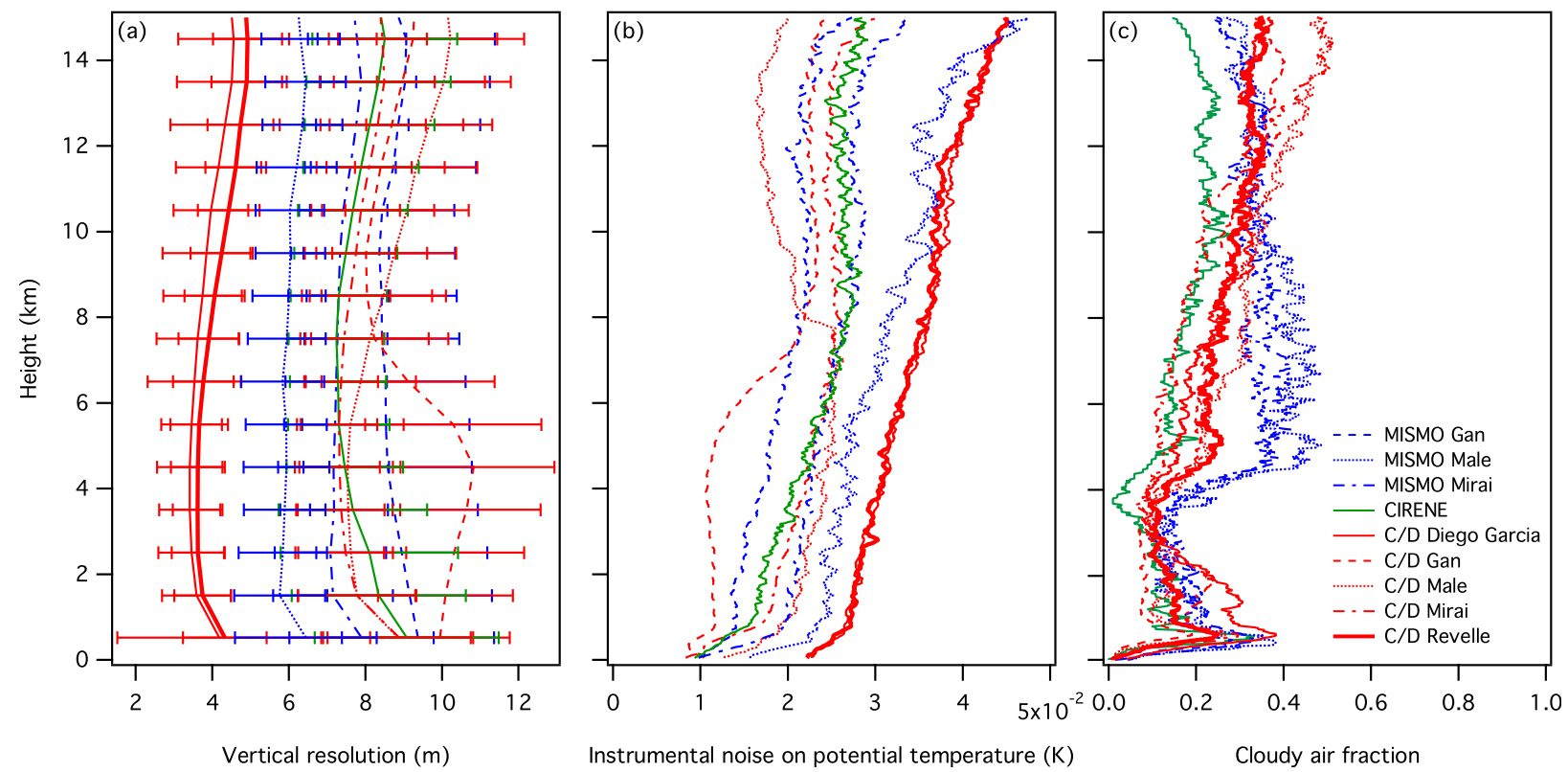

FIG. 2. Vertical profiles of (a) mean vertical resolution of radiosondes (segments are standard deviations), (b) mean instrumental noise on potential temperature (estimated from noise standard deviation on temperature and pressure interpolated on a regular 7-m grid), and (c) cloudy-air fraction, with the corresponding data source designated by line style and color.

and undersampling by a given factor) is needed-in our case, by a factor of 3 , resulting in a reduction of our vertical resolution to $21 \mathrm{~m}$. The corresponding average tnr values, computed on the degraded resolution profiles, are given for each campaign in Table 1.

The regularly gridded potential temperature profiles are sorted from the ground up to obtain a monotonically increasing potential temperature profile. The Thorpe displacements are then determined by $D(i)=[i-R(i)] d z$ where $R(i)$ is the rank of the $i$ th bin in the corresponding reordered profile and $d z=21 \mathrm{~m}$. Inversions are then defined as the portion of the potential temperature profiles having $n$ points where $\Sigma_{i=1, n} D(i)=0$ and $\sum_{i=1, k} D(i)<0$ for any $k<n$. This ensures that displacements are negative (positive) at the bottom (top) of an inversion (W10). Among these inversions, the actual overturns are retained if the range of their $\theta$ variation exceeds the 99th percentile of possible ranges for samples of equivalent size and $\sigma_{N}$ standard deviation. The tabulated percentiles of the range for normally distributed random variables as a function of the sample size can be found in W10. For each overturn detected on these smoothed and undersampled profiles $(d z=21 \mathrm{~m})$, turbulence statistics (Thorpe length, Brunt-Väisälä frequency, vertical shear, and eddy diffusivities) are computed on the original regularly gridded profiles $(d z=7 \mathrm{~m})$. In particular, the Thorpe length scale $L_{T}$ is diagnosed as the rms of the Thorpe displacements within a given overturn.
The Thorpe length scale $L_{T}$ is thought to be linked with the Ozmidov scale $L_{O}$ (Ozmidov 1965) by a simple multiplicative coefficient, although large variability has been found in the relationship between the two (e.g., Schneider et al. 2015). The Ozmidov scale $L_{O}$ is a function of both the turbulent kinetic energy dissipation rate and the Brunt-Väisälä frequency. It corresponds to the scale for which inertia and buoyancy forces are in equilibrium and represents the upper limit of eddy size under a given stratification and for a given turbulence intensity. Within each overturn, the eddy diffusivity can be computed as $K_{z}=\gamma C_{K} L_{T}^{2} N$ (Gavrilov et al. 2005; Clayson and Kantha 2008), where $N$ is the BruntVäisälä frequency computed on the reorganized stable profile of $\theta$ (Wilson et al. 2014) and with mixing efficiency $\gamma=0.25$. The value of $C_{K}$ (the square of the multiplicative constant between $L_{T}$ and $L_{O}$ ) is largely uncertain and may depend on the type of turbulent event (Gavrilov et al. 2005; Clayson and Kantha 2008; Wilson et al. 2014; Schneider et al. 2015; Fritts et al. 2016). Following, Kantha and Hocking (2011), we take $C_{K}=1$ in our computations, as they found it gives the best agreement with radar-derived estimates. In addition to this uncertainty on the order of magnitude of the eddy diffusivity coefficient for one single turbulent event, the computation of an effective eddy diffusivity corresponding to the resulting effect of several stochastic mixing events is also subject to large uncertainties. Several models have been proposed to 
estimate this effective eddy diffusivity (e.g., Dewan 1981; Woodman and Rastogi 1984; Vanneste and Haynes 2000; Wilson 2004). These models, however, largely depend on parameters that are hard to constrain experimentally (in particular, the turbulent air fraction and the distributions of overturn sizes and of turbulence lifetime). The resulting uncertainties on the associated turbulent fluxes (e.g., the vertical turbulent moisture flux) are thus very large (Bellenger et al. 2015b).

Wilson et al. (2013) proposed an approach to take into account the static stability decrease that is due to the latent heat release by water condensation in cloudy saturated air. They showed that nonconvective clouds are often turbulent and are responsible for a significant part of atmospheric turbulence. In our case, however, it is difficult to accurately categorize the convective nature of clouds identified as saturated air parcels in the soundings. Therefore, we focus on turbulence outside of clouds for which the formulation of turbulence parameters in a stratified environment is valid. We then use the simplified approach of Wilson et al. (2013) based on Zhang et al. (2010) to remove cloudy sections of the profiles before performing the Thorpe analysis.

The calculation of the gradient Richardson number $\mathrm{Ri}_{g}$, Brunt-Väisälä frequency $N$, and vertical shear of the horizontal wind (here called vertical shear) requires the computation of vertical derivatives. These derivatives have to be computed over relatively largealtitude ranges $\Delta z$ in order to have a reasonable number of data points for computing the linear regression. Conversely, $\mathrm{Ri}_{g}$ is strongly scale dependent (Balsley et al. 2008); thus, $\Delta z$ needs to be minimized in order to capture fine details. To compromise, we chose $\Delta z=$ $200 \mathrm{~m}$ ( 29 points on the 7 -m profiles) for computing the vertical derivatives necessary for $\mathrm{Ri}_{g}$ and $N$. Finally, note that (i) the vertical shear calculations is here defined in order to take into account both the change in horizontal wind speed and direction and (ii) that $N$ is computed on the reorganized stable profile.

One can question the homogeneity of our dataset and to what extent it represents conditions characteristic of the open ocean. In fact, there was a discernable island effect detectable by S-band radar on Gan Atoll for a limited time period on 19 separate days during $\mathrm{C} / \mathrm{D}$, with observable effects as high as $2.5-3 \mathrm{~km}$ in the most extreme cases. However, the island effect was generally confined well below $2 \mathrm{~km}$. And since the more extreme cases resulted in the production of clouds, these sounding sections were generally removed from our analysis when sampled (refer to the discussion above). Spatially, the apparent region of island influence was both linear and extremely narrow in the horizontal. This enabled several rawinsondes to exit the affected region laterally rather than vertically. Furthermore, Davison (2014) showed that, over Gan Atoll, the island effect was statistically detectable only within the lowest $1 \mathrm{~km}$. Therefore, the impact of these small islands on the soundings measurements above $1-\mathrm{km}$ height will be neglected. The fact that no difference arises between island-based or vessel-based diagnostics in the profiles of turbulent fraction (not shown) lends support to this decision. In addition, when considering the temporal spectra of the turbulent fraction evolution for the boundary layer and lower and upper troposphere, there is no difference except for the diurnal peak in the island boundary layer (not shown). We can note that this diurnal peak is present for all observations sites (land and sea) in the upper troposphere, as already observed between 11 and $17 \mathrm{~km}$ by Liu et al. (2014) over ocean. Based on these considerations, we treat our dataset as homogeneous and representative of open ocean above $1 \mathrm{~km}$.

\section{c. Gravity wave activity}

A large number of studies use radiosonde observations in order to characterize internal GWs (e.g., Barat 1983; Fritts et al. 1988a; Tsuda et al. 1994a,b; Karoly et al. 1996; Reeder et al. 1999; Lane et al. 2003; Gong and Geller 2010; Hankinson et al. 2014a,b). GWs can be diagnosed from their signature in horizontal wind, temperature, and vertical wind. The latter is diagnosed from the perturbations of the balloon ascent rate (Reeder et al. 1999; Lane et al. 2003). Note that this ascent rate does not simply represent the air vertical velocity. Gallice et al. (2011) show that a precise model of the balloon ascent in still air may be necessary to accurately retrieve this parameter. Yet they also show that the use of such a model does not strongly impact the estimate of the finer fluctuations we are interested in: namely, those variations over distances of a few kilometers. Note too that drag on a balloon may be reduced when it encounters turbulence, leading to vertical acceleration not directly associated with GWs (Gallice et al. 2011). However, the composite obtained based on balloon ascent rate actually shows characteristics of GWs (see below). Using these parameters (horizontal wind, temperature, and vertical ascent rate) enables us to focus on different parts of the GW spectrum (Fritts et al. 1988a; Lane et al. 2003; Gong and Geller 2010; Geller and Gong 2010; Hankinson et al. 2014a,b). Indeed, Lane et al. (2003) showed from theoretical arguments that low-frequency, near-inertia-GWs have a stronger signature in horizontal wind, while higherfrequency GWs are characterized by a stronger signal in the vertical velocity field. In contrast, perturbations in temperature are considered to reflect both low- and 


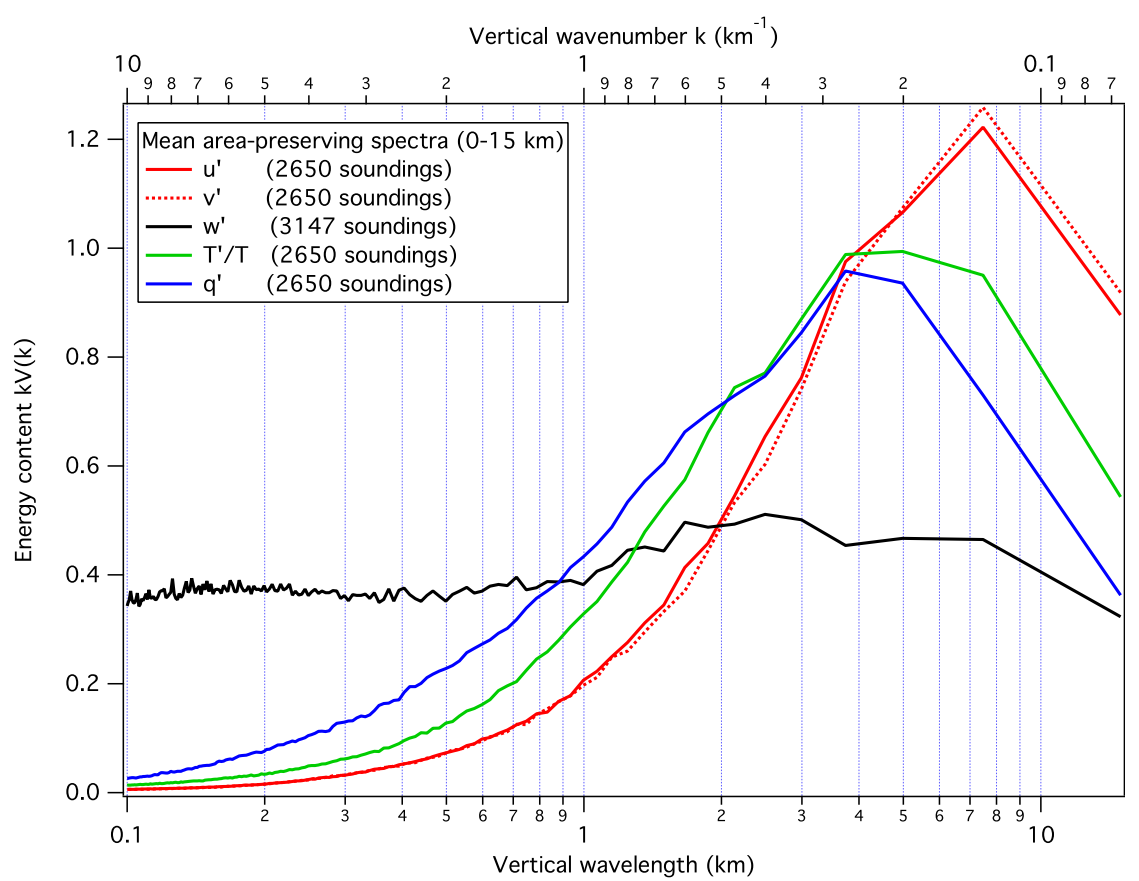

FIG. 3. Normalized mean energy conservative power spectra for perturbations of zonal wind $u^{\prime}$ (solid red), meridional wind $v^{\prime}$ (dotted red), balloon vertical ascent rate $w^{\prime}$ (black), normalized temperature $T^{\prime} / T$ (green), and specific humidity $q^{\prime}$ (blue) for the whole set of soundings. Perturbations are computed relative to a 5-day running mean (see section $2 \mathrm{c}$ for details).

high-frequency GWs. For brevity, GWs characterized by their signature in horizontal wind, normalized temperature, and vertical ascent will be denoted GWus, GWTs, and GWws, respectively.

For each sounding that reaches at least $15-\mathrm{km}$ height, we compute the perturbation $X^{\prime}(t, z)$ (with $X$ being either the temperature, wind speed, or vertical ascent rate) by removing the slowly varying background using a 5-day running mean centered on the considered profile. Because the time resolution varies with site and time, this corresponds to average profiles constructed on 10-40 consecutive soundings. What is thus being removed from each profile is defined as the background $X(t, z)$. This is particularly important for computation of the normalized temperature, $T^{\prime}(t, z) / T(t, z)$, which is the ratio of temperature perturbation to the background temperature as a function of height. Vertical spectra (Fig. 3) are computed from these perturbation profiles between the surface and $15 \mathrm{~km}$. Because we are also interested in perturbations close to the surface, we do not apply any windowing prior to taking the Fourier transform.

We then filter the obtained perturbation to focus on GWs characterized by $1-5-\mathrm{km}$ vertical wavelengths that represent a large part of the variance. To this end, we further extract $\mathrm{GW}$-associated perturbations following Lane et al. (2003) by removing from each profile a cubic polynomial fit and the vertically moving $5-\mathrm{km}$ boxcar average of the remainder. This removes perturbations with a vertical scale of more than $5 \mathrm{~km}$. Note that, by doing so, we filter out larger vertical wavelengths associated with moist convection. We then remove perturbations with vertical wavelength less than $1 \mathrm{~km}$ using a simple low-pass filter. The obtained filtered perturbations are then presumed to primarily represent mainly GWs, as discussed by Lane et al. (2003). This assumption will be tested by the composite analysis described below. Note that we do not consider filtered perturbations below 1-km height and above 14-km height in order to avoid boundary issues.

Taking these filtered perturbations, $X_{f}^{\prime}$, as references, we construct composites of 1) unfiltered perturbations of zonal and meridional wind $\left(u^{\prime}\right.$ and $\left.v^{\prime}\right)$, balloon ascent speed $w^{\prime}$, normalized temperature $T^{\prime} / T$, and specific humidity $q^{\prime}$ and of 2) raw profiles of turbulent and cloud fractions, Richardson number, Brunt-Väisälä frequency, and vertical shear. For a given reference parameter $\left[u_{f}^{\prime}, w_{f}^{\prime}\right.$, or $\left.\left(T^{\prime} / T\right)_{f}\right]$, we first compute the overall standard deviation of the low-pass-filtered signal. We then detect all filtered perturbation extrema with absolute values greater than the standard deviation (a large maximum in between two large successive minima). The composite $\mathrm{GW}$ is then computed on 101 bins of variable length 
centered on the maximum and covering four complete wave cycles so that maxima and minima are averaged together. The corresponding vertical wavelength is simply computed as the distance between the two selected minima. Statistical significance of the composite is tested using the Student's $t$ test at the 99\% level considering a degree of freedom equal to the number of selected cases. To study the link between GW activity and climate variability, GW temporal indices are defined as the standard deviation of the filtered perturbations of the considered parameter $\left(\sigma_{X_{f}^{\prime}}\right)$ for a given height interval: namely, the lower troposphere $(1-7 \mathrm{~km})$ and the upper troposphere $(7-15 \mathrm{~km})$.

In Fig. 2a, a systematic and abrupt change in the vertical resolution of Gan Island soundings during C/D can be seen around 5-6-km height. This impacts the computed ascent rate and thus the vertical velocity perturbations used to diagnose GW activity. Therefore, results are recomputed without taking C/D Gan Island observations into account. The results presented here are robust and insensitive to the inclusion of Gan Island observations (not shown).

\section{d. Environment variability indices}

A first inspection of the results shows that turbulence tends to be stronger during relatively dry periods with weak convective activity in the lower troposphere [see also Bellenger et al. (2015b) and below]. A simple index defined as the mean specific humidity between 2 and $4 \mathrm{~km}$ is computed for each sounding to separate the dry and the humid cases. Soundings with a mean specific humidity lower (higher) than the average minus (plus) a standard deviation are considered to be dry (humid). One should note that this simple definition does not identify local dry-air intrusions, such as those discussed by Kerns and Chen (2014). Dry intrusions are thus treated together with large-scale dry conditions associated with subsidence.

Tropical depressions and cyclones are well-known sources of internal GWs (e.g., Ki and Chun 2010). The tropical depression vortices (TDV) associated with these systems are tracked based on the approach described in Duvel (2015) and using ERA-Interim meteorological fields. A TDV area is defined as contiguous grid points with the geopotential anomaly of the $850-\mathrm{hPa}$ isobar lower than a given adaptive threshold, where the geopotential anomaly $\Delta \varphi$ is taken with respect to a $\pm 7.5^{\circ}$ smoothed field. The TDV area is computed for the series of contours with values more negative than a set minimum (e.g., $\Delta \varphi<-80 \mathrm{~m}^{2} \mathrm{~s}^{-2}$ ), and the TDV area is defined by the first qualifying contour encompassing an area with an equivalent radius of less than $3^{\circ}$ of latitudelongitude. The tracking of a given TDV is performed by considering the overlap between TDV areas of two consecutive time steps. We consider that a vortex is in the vicinity of the observation sites if it is within the region extending from $20^{\circ} \mathrm{S}$ to $0^{\circ}$ and from $60^{\circ}$ to $100^{\circ} \mathrm{E}$ (see Fig. 1). We choose not to include Northern Hemisphere TDV as most of the soundings are obtained in the Southern Hemisphere. Note, however, that if the results obtained are indeed quantitatively sensitive to the choice of this region, they are qualitatively robust (not shown).

Finally, in order to characterize MJO activity, we simply rely on the widely used Wheeler and Hendon (2004) Real-time Multivariate MJO (RMM) index. This index is based on the projection of equatorial anomalies of outgoing longwave radiation (OLR) and zonal wind at 850 and $200 \mathrm{hPa}$ onto a couple of empirical orthogonal functions (EOFs). For a given day, the index defines the MJO amplitude and a phase, which reflect the geographical position of the MJO-associated convection. Using standard thresholding, we consider the MJO to be active when the amplitude of the index is greater than 1.

\section{General characteristics of turbulence over the Indian Ocean}

Figure 4 provides basic statistics on turbulence observed in the troposphere over the tropical Indian Ocean for the three field campaigns. These statistics provide an extension of those presented in Bellenger et al. (2015b), which is limited to the lower freetroposphere observations (between 1- and 5-km height) from R/V Mirai during C/D. For the whole dataset, a total of about $1.4 \times 10^{5}$ inversions are detected (Fig. 4a). Of these, only $15 \%$ are associated with a $\theta$ variation exceeding the 99 th percentile of instrument noise and can thus be interpreted as real overturns. As noted in W10, this condition removes most of the smaller inversions with sizes close to the effective resolution of our dataset and which are therefore difficult to separate from instrumental noise. The detected overturns have a minimum size of $\sim 63 \mathrm{~m}$ (i.e., three-datapoint inversions on the $21-\mathrm{m}$ undersampled profiles and nine-data-point inversions on the $7-\mathrm{m}$ original regular profiles used to compute turbulence statistics). The distribution peaks at $\sim 80-140 \mathrm{~m}$, while the deeper turbulent regions have sizes of $\sim 1 \mathrm{~km}$. The eddy diffusivity $K_{z}$ simply characterizes the turbulence within these overturns. These $K_{z}$ values are linked to the square of vertical length scale of the turbulent regions and to the local Brunt-Väisälä frequency. Their distribution (Fig. 4b) shows great variability, with the majority of $K_{z}$ values spanning over three orders of magnitude from 1 to $100 \mathrm{~m}^{2} \mathrm{~s}^{-1}$ and with a peak in the distribution around 

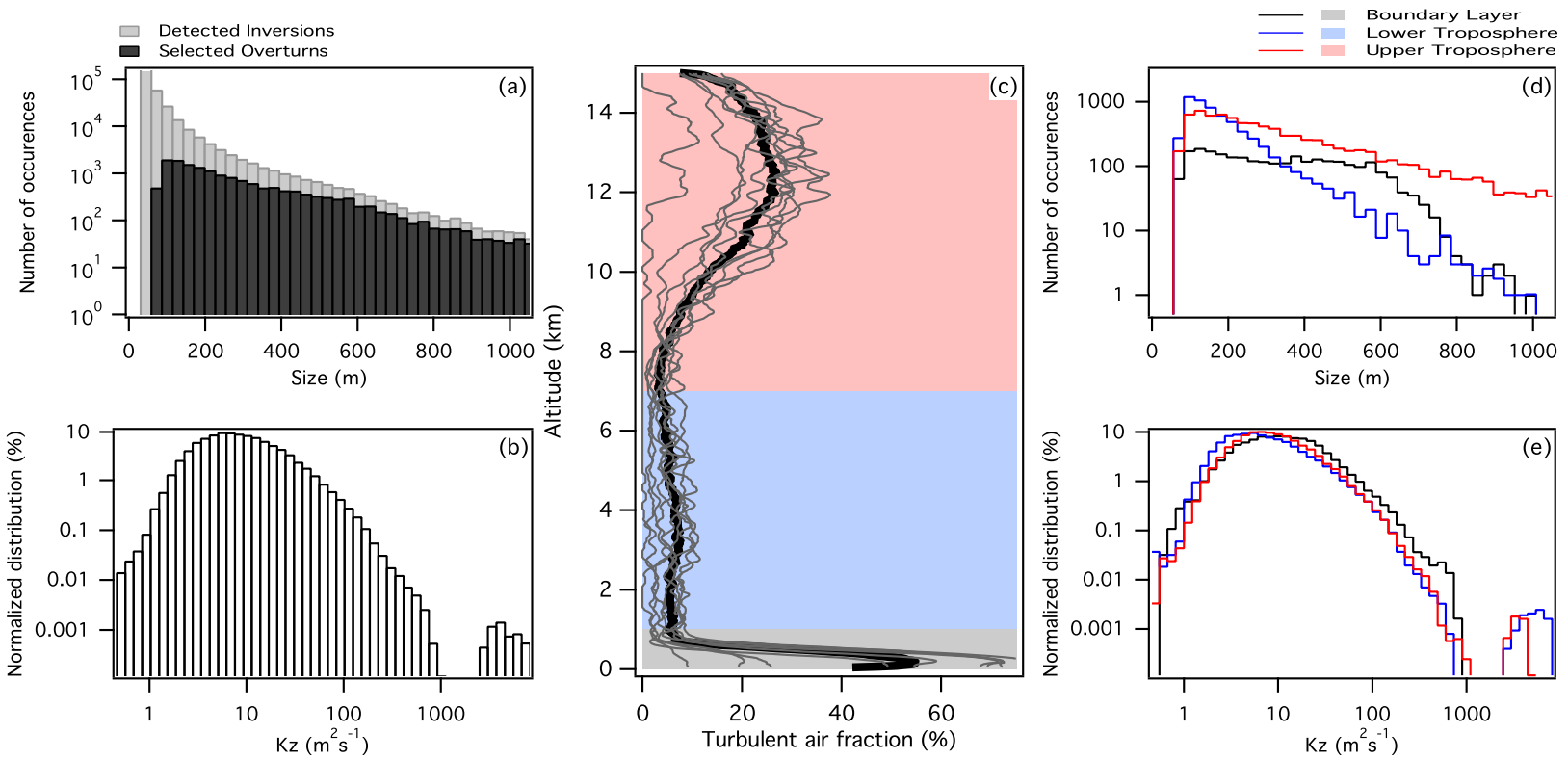

FIG. 4. (a) Frequency of occurrence by size of all detected inversions (gray) and selected overturns (black) between the surface and 15-km height. (b) Distribution of the eddy diffusivity coefficients $K_{z}$ within each of these overturns (normalized; \%). (c) The total clear-air turbulent fraction (\%) for all campaigns (thick black line) and for each of the individual nine campaigns (thin gray lines) smoothed over $200 \mathrm{~m}$. (d) Frequency of occurrence by size of the overturns and (e) distribution of the eddy diffusivity coefficients (\%) in the boundary layer (black; $0-1 \mathrm{~km}$ ), the lower troposphere (blue; $1-7 \mathrm{~km}$ ), and the upper troposphere (red; $7-15 \mathrm{~km}$ ). The colors correspond to the three vertical domains shaded in (c).

$5-10 \mathrm{~m}^{2} \mathrm{~s}^{-1}$. The scale of these values is comparable to those reported in previous campaigns [see Wilson (2004), Wilson et al. (2014), and references herein].

Vertical profiles of turbulent fraction (relative to clear air) for the different campaigns and observations sites (Fig. 4c) highlight three distinct vertical domains: the turbulent boundary layer below $1 \mathrm{~km}$ (gray) with turbulence frequency sometimes exceeding $50 \%$; the lower free troposphere between 1 and $7 \mathrm{~km}$ (blue) with turbulence activity of $5 \%-15 \%$; and the upper troposphere above $7 \mathrm{~km}$ (red) with maximum turbulence frequency of $\sim 30 \%$. In spite of differences due to different observing techniques or the geographical and seasonal variation of turbulence sources (such as convection), these relative fractions of turbulence frequency in the three vertical domains are comparable to what is reported by Wilson et al. (2005) above Japan using radar and by Cho et al. (2003) above the Pacific Ocean using aircraft observation below $8-\mathrm{km}$ height. Using radiosondes above India, Nath et al. (2010) reported a similar shape to the turbulent fraction profile, but the peak in their estimate at $\sim 50 \%$ in the upper troposphere is certainly overestimated because of their treatment of the instrumental-noise issue (W10). On the other hand, our turbulent fraction estimate in the upper troposphere may appear large when compared to the estimate derived from commercial aircraft turbulence observations over the United States (Sharman et al. 2014). In addition to possible geographical differences with our region of interest, the commercial aircraft dataset may have issues diagnosing light turbulence. It is also subject to a "turbulence avoidance" bias as a result of pilots avoiding regions with high probabilities of strong turbulence.

Overturn size and eddy diffusivity distributions for the three vertical domains defined on Fig. $4 c$ are given in Figs. $4 \mathrm{~d}$ and $4 \mathrm{e}$, respectively. Most of the turbulent regions and the thickest ones are found in the upper troposphere above $7 \mathrm{~km}$. Compared to the systematic decrease in the number and vertical extent of overturns observed in the free troposphere, the boundary layer distribution is relatively flat, with frequent regions between $150-$ and 500-m depth (Fig. 4d). These values are consistent with the turbulent boundary layer depth diagnosed over tropical oceans (e.g., Johnson et al. 2001; Bellenger et al. 2010; Davison et al. 2013a,c). It is interesting to note that eddy diffusivities in the larger turbulent regions of the upper troposphere (Fig. 4e) are comparable to these in the smaller turbulent regions of the lower free troposphere.

These comparisons can be better understood in light of the mean profiles of potential temperature, BruntVäisälä frequency, wind speed, and shear provided in Fig. 5. Both the boundary layer and the upper troposphere near $12 \mathrm{~km}$ are characterized by reduced static stability (Figs. 5a,b), which facilitates turbulence 

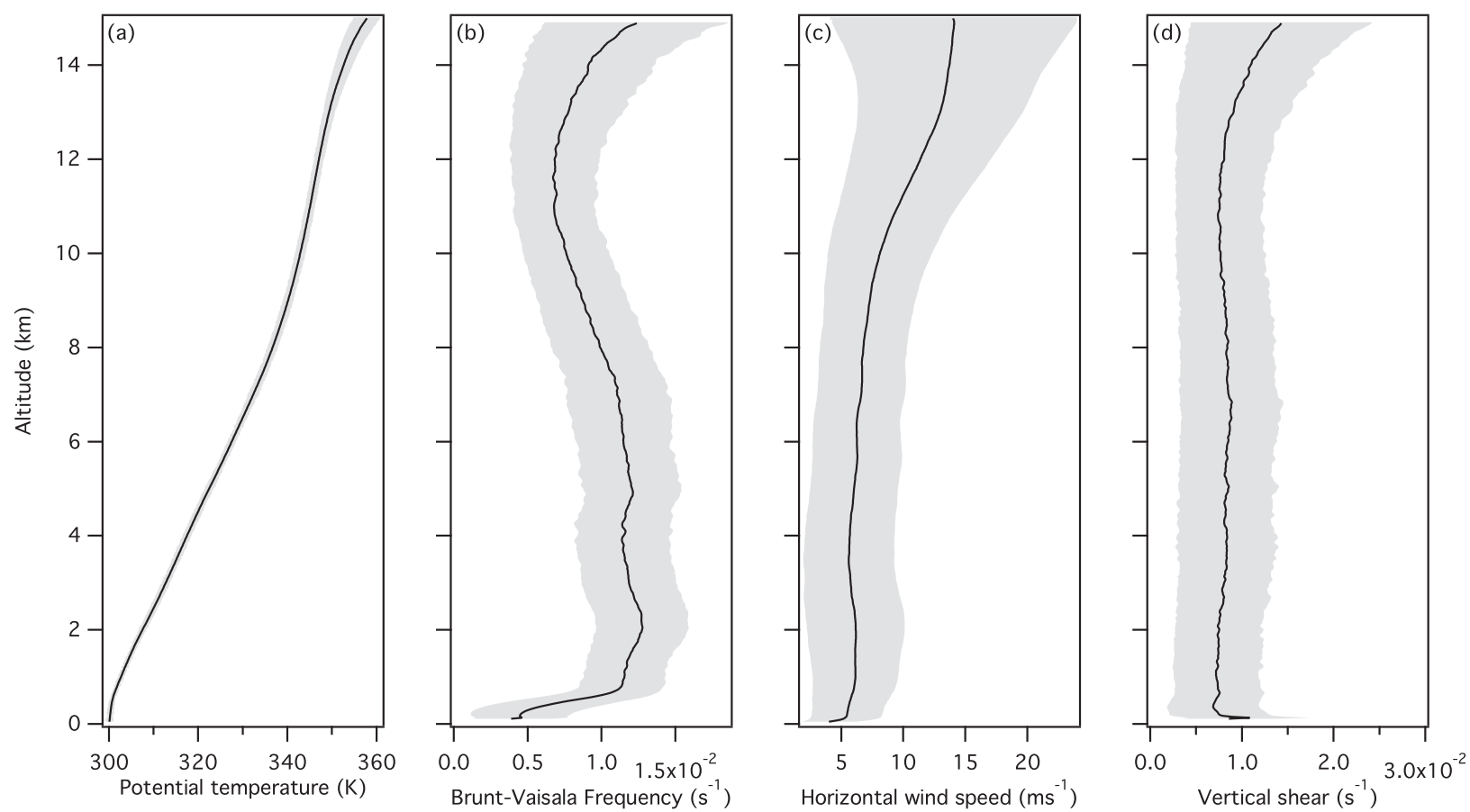

FIG. 5. Mean profiles (black) and standard deviation (gray shading) of (a) potential temperature (K), (b) Brunt-Väisälä frequency ( ${ }^{-1}$ ), (c) horizontal wind speed $\left(\mathrm{m} \mathrm{s}^{-1}\right)$, and $(\mathrm{d})$ vertical shear $\left(\mathrm{s}^{-1}\right)$ for the whole dataset.

occurrence. Note also the slight decrease in stability between 2.5- and 4-km heights that is associated with a slight increase in turbulence frequency (Fig. 4c). Average horizontal wind speed tends to increase regularly between 10- and 13-km height (Fig. 5c), and the shear (wind speed and direction) is relatively constant (Fig. 5d) until it approaches the tropopause. Thus, for these cases, the dominant control on turbulence frequency seems to be stability. Of course, as the turbulence tends to reduce both stability and shear, we cannot draw this conclusion from the mean profiles alone. In addition, according to the $K_{z}$ formulation from Gavrilov et al. (2005), the reduced stability may also explain the limitation of the eddy diffusivities diagnosed in the boundary layer and in the upper troposphere (Fig. 4e), despite the increase in the depth of the diagnosed turbulent regions' vertical extents (Fig. 4d). For the rest of the paper, we will focus on turbulence characteristics above the turbulent boundary layer (i.e., for heights above $1 \mathrm{~km}$ ), where the island effect can be neglected (Davison 2014).

Figure 6 shows distributions of Brunt-Väisälä frequency, vertical shear, and Richardson number for points inside (solid) and outside (dashed) overturns in both the upper (red) and lower (blue) free troposphere. Within overturns, the static stability is significantly reduced when compared to normal conditions (Fig. 6a). Of course, this may be partly due to the turbulence itself. However, here the Brunt-Väisälä frequency is computed on the monotonic reordered potential temperature profile, which we presume to be representative of the turbulent environment. Therefore, no unstable profile enters these statistics. In comparison, there is hardly any change in the distributions of vertical shear except a tendency to observe stronger shear outside of overturns in the upper troposphere (Fig. 6b). Thus, stability changes may account for the changes in Richardson number (Fig. 6c) that exhibit smaller values within the overturns. Interestingly, Richardson numbers are weaker in the upper troposphere outside of the overturns, indicating that turbulence is more likely to occur there than in the lower troposphere. It is well known that GWs are phenomena that can locally reduce the static stability or even overturn and lead to turbulence, as inferred from theoretical considerations by Hodges (1967), Chao and Schoeberl (1984), and Fritts and Dunkerton (1985) and as shown in observations by Fritts et al. (1988b). These studies showed in particular that turbulence is localized in the portion of the wave characterized by reduced static stability rather than in portions characterized by large shear.

\section{Link between turbulence and GW over the Indian Ocean}

Figure 7 illustrates the Thorpe analysis and its link with the variability of the environment for Gan Atoll 

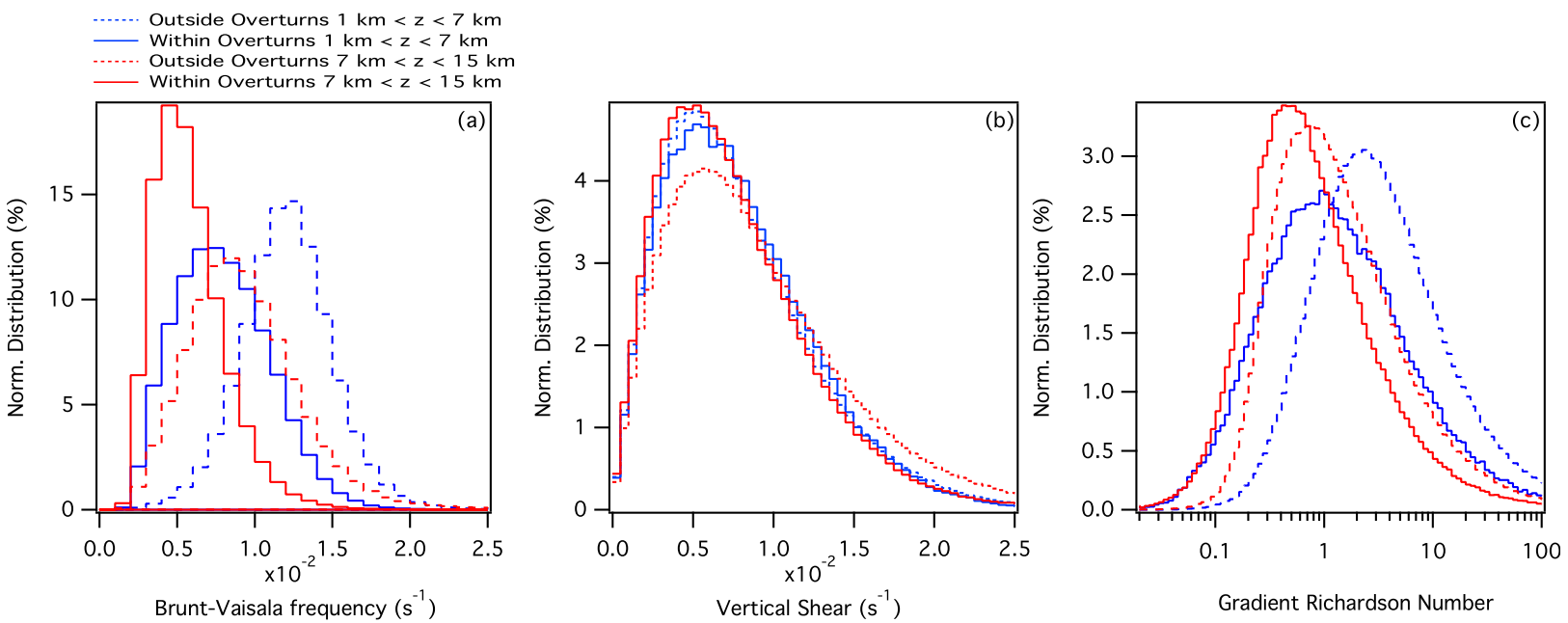

FIG. 6. Distribution of (a) Brunt-Väisälä frequency $\left(\mathrm{s}^{-1}\right)$, (b) vertical shear $\left(\mathrm{s}^{-1}\right)$, and (c) gradient Richardson number inside (solid) and outside (dashed) the overturns for the lower troposphere (blue) and the upper troposphere (red).

during C/D. Figure 7a shows the time-height evolution of turbulent regions and its relation to specific humidity for the whole observation period. Consistent with Fig. 4c, turbulent regions are most frequent in the planetary boundary layer and in the upper troposphere. In the lower free troposphere $(1-7 \mathrm{~km})$, turbulence is more intermittent with higher frequency during relatively dry periods (e.g., 2-12 and 30-31 October, 30 November-8 December, and from 26 December until the end of the observation period). Another example is given by Bellenger et al. (2015b, their Fig. 1), suggesting that this is a robust feature of turbulence in the lower troposphere above tropical oceans. The three other panels of Fig. 7 focus on the 5-22 January dry period (gray frame on Fig. 7a). Figure $7 \mathrm{~b}$ suggests some link between turbulence and moisture vertical gradients below $8-\mathrm{km}$ height already noted by Bellenger et al. (2015b). These anomalous moisture vertical gradients are comparable to those observed by Luce et al. (2010b) and Davison et al. $(2013 \mathrm{~b}, \mathrm{c})$ and are characterized by vertical scales ranging from a few hundreds of meters to $1 \mathrm{~km}$ (thus a wavelength of up to $2 \mathrm{~km}$ ). This link between the occurrence of turbulence and finescale moisture variations is visible in particular during 5-10 and 18-22 January around 3-4 km and during 10-18 January between 6 - and 7-km heights.

Internal GWs typically have vertical wavelengths of a few kilometers in the troposphere (e.g., Fritts et al. 1988a; Tsuda et al. 1994b; Shimizu and Tsuda 1997; Reeder et al. 1999; Lane et al. 2003; Leena et al. 2012; Hankinson et al. 2014a). In Figs. 7c and 7d, the perturbations of zonal wind and normalized temperature for the same dry period are shown (refer to section $2 b$ ). Distinct variations, which can be interpreted as a GW signature, are visible on both panels. Up- and downward phase propagation can be seen. These features are consistent with observations reported by Tsuda et al. (1994b) above the mountainous island of Java, for example. Turbulence appears to be associated with these perturbations and can be observed between strong zonal wind or temperature anomalies from $12-\mathrm{km}$ height on 10 January and gradually downward to $9-\mathrm{km}$ height on 15 January (Figs. 7c,d). Note, however, that wind and temperature perturbations are not always clearly associated with one another. An example can be seen between 4- and 8-km heights from 10 to 12 January: there is a clear downward phase propagation in zonal wind anomalies (Fig. 7c) and an upward one in temperature perturbations (Fig. 7d).

Figure 3 shows the mean vertical power spectra for zonal and meridional wind perturbations, balloon ascent rate, GW normalized temperature, and specific humidity anomalies computed on the profiles processed using the Lane et al. (2003) approach (see section 2c). The spectra of zonal and meridional wind peak at $7.5-\mathrm{km}$ vertical wavelength, while temperature and moisture spectra peak around $3-5 \mathrm{~km}$. The vertical ascent rate spectrum also exhibits a maximum around $2-3 \mathrm{~km}$, but with a relatively flat spectrum. These spectra are consistent with previous studies (Fritts et al. 1988a; Reeder et al. 1999; Gong and Geller 2010; Hankinson et al. 2014a) and, in particular, with the fact first discussed by Lane et al. 2003 that ascent rate perturbations emphasize waves with shorter vertical wavelength. Spectral maxima for $T^{\prime}$ and $w^{\prime}$ are found within the $1-5-\mathrm{km}$ band chosen for GW filtering.

Composited GW perturbations $\left(X^{\prime}=u^{\prime}, v^{\prime}, w^{\prime}, T^{\prime} / T\right.$, and $q^{\prime}$ ) are obtained using either maxima in normalized 


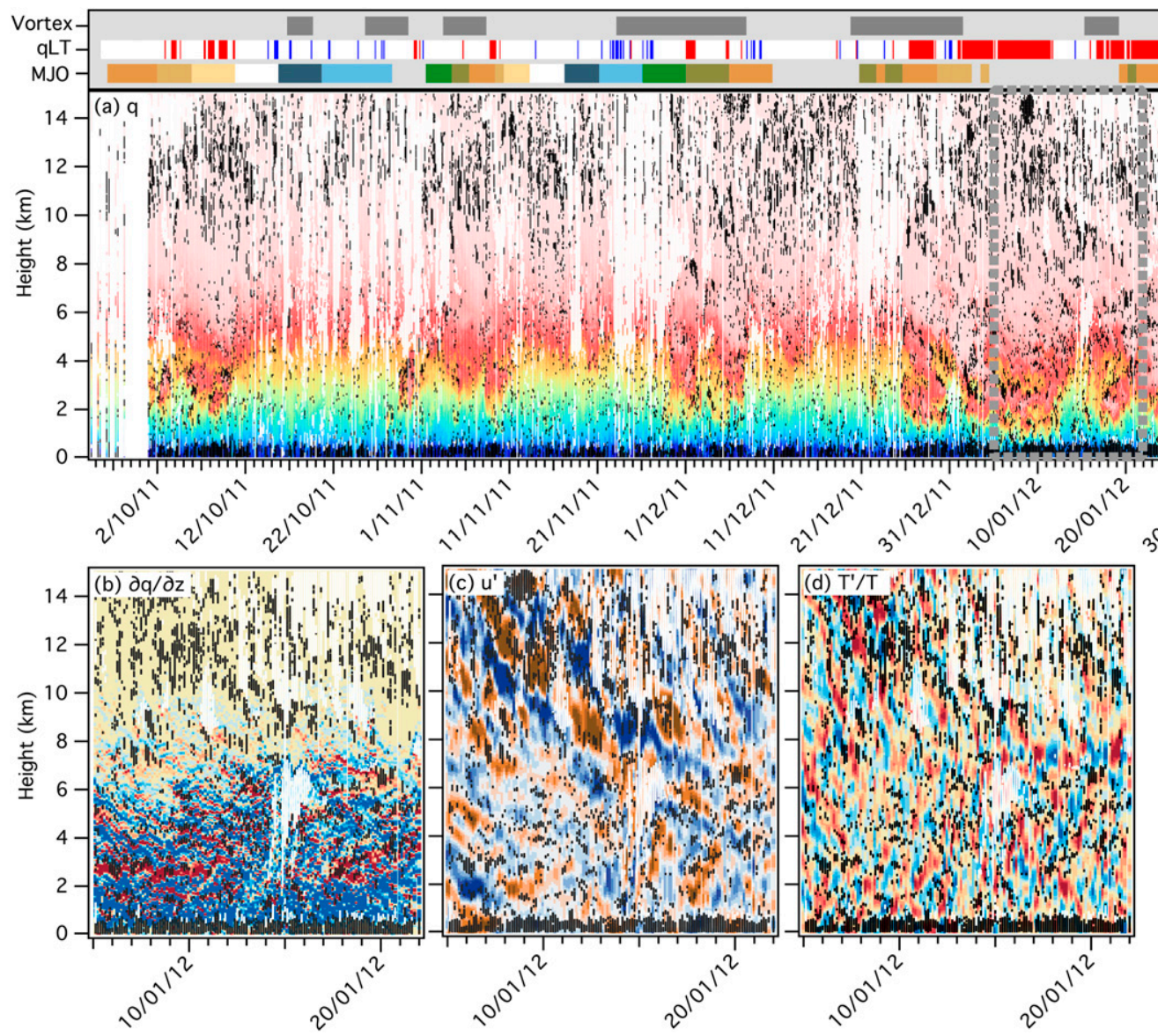

FIG. 7. (a) Time-height plot of turbulence occurrence (black segments) and specific humidity ( $\mathrm{g} \mathrm{kg}^{-1}$; colors) for the whole observation period based on Gan soundings during C/D. Bar graphs above (a) indicate the following: (top) vortex presence (gray) within $20^{\circ} \mathrm{S}-0^{\circ}$, $60^{\circ}-100^{\circ} \mathrm{E}$ (refer to Fig. 1); (middle) driest (red) and wettest (blue) periods; and (bottom) MJO phase evolution (by color) for MJO amplitude $>1$ as defined by Wheeler and Hendon (2004). (b) Specific humidity vertical gradients $\left(\mathrm{g} \mathrm{kg}^{-1} \mathrm{~m}^{-1}\right)$, (c) zonal wind filtered perturbations $u_{f}^{\prime}\left(\mathrm{m} \mathrm{s}^{-1}\right)$, and (d) normalized temperature filtered perturbations $\left(T^{\prime} / T\right)_{f}$ for the 5-22 Jan 2012 period [marked by the gray frame on (a)]. Cloudy regions in (a) and (b) are shaded in white.

temperature 1-5-km filtered perturbations, $\left(T^{\prime} / T\right)_{f}$, (GWT; Fig. 8), or maxima in ascent speed 1-5-km filtered perturbations, $w_{f}^{\prime}(\mathrm{GWw}$; Fig. 9) as reference heights. Only $\left(T^{\prime} / T\right)_{f}$ and $w_{f}^{\prime}$ perturbations having peak-to-peak variations of more than two standard deviations were used. Each GW perturbation is normalized so that the apparent vertical wavelength for reference profile, either $\left(T^{\prime} / T\right)_{f}$ or $w_{f}^{\prime}$, is 1 . Figure 10 shows the distributions of apparent vertical wavelengths and of the corresponding altitudes of the perturbation maxima used to compute the composited GWs. Note that no attempt is made to separate downward- and upward-propagating waves.

Figure 8a shows composites based on GW filtered normalized temperature perturbations $\left(T^{\prime} / T\right)_{f}(\mathrm{GWT}$; green line). These events most commonly correspond to apparent vertical wavelengths between 2 and $3 \mathrm{~km}$ (Fig. 10a, green). They are more frequent in the lower troposphere (Fig. 10b, green), where the stability is higher (Fig. 5). Dynamical perturbations in phase quadrature are associated with these temperature variations. In particular, it is interesting to note that, even if no particular selection was made concerning the relationship between $\left(T^{\prime} / T\right)$ and $u^{\prime}$, the zonal wind perturbation would reach $1 \mathrm{~m} \mathrm{~s}^{-1}$ amplitude above the temperature maximum perturbation. Note that this phase relationship is even clearer when considering composited $u_{f}^{\prime}$ (not shown). On the other hand, meridional wind perturbations do not survive this composite procedure. Indeed, $60 \%$ of the selected $\left(T^{\prime} / T\right)_{f}$ perturbations correspond to $u_{f}^{\prime}(1 / 2)>0$, and $40 \%$ to $u_{f}^{\prime}(1 / 2)<0$, whereas no such asymmetry is apparent for meridional wind perturbations. The reason for this may be linked to the dominance of certain types of Kelvin waves in the GWT ensembles. However, a detailed study of the wave types involved in this composite is beyond the scope of this article and must be reserved for future work. 

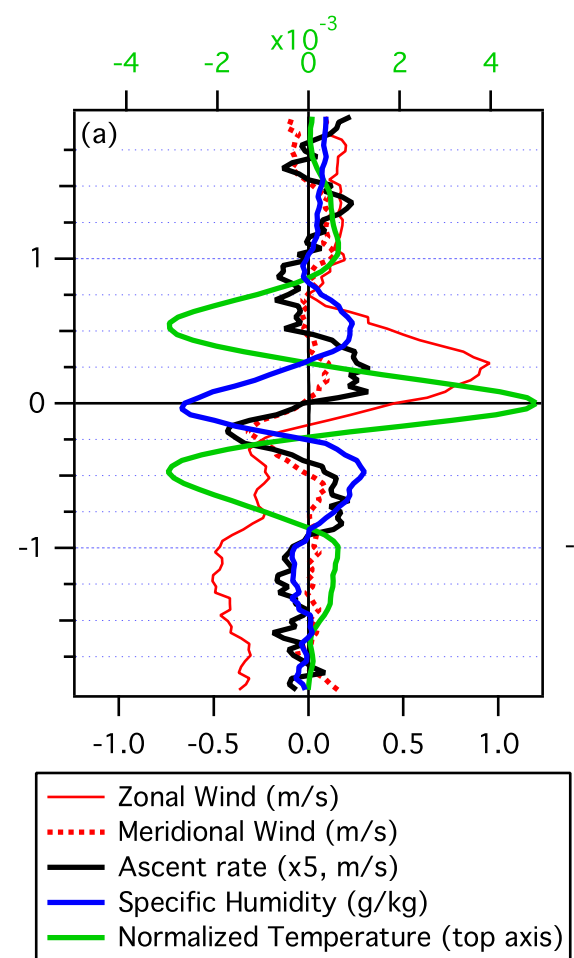
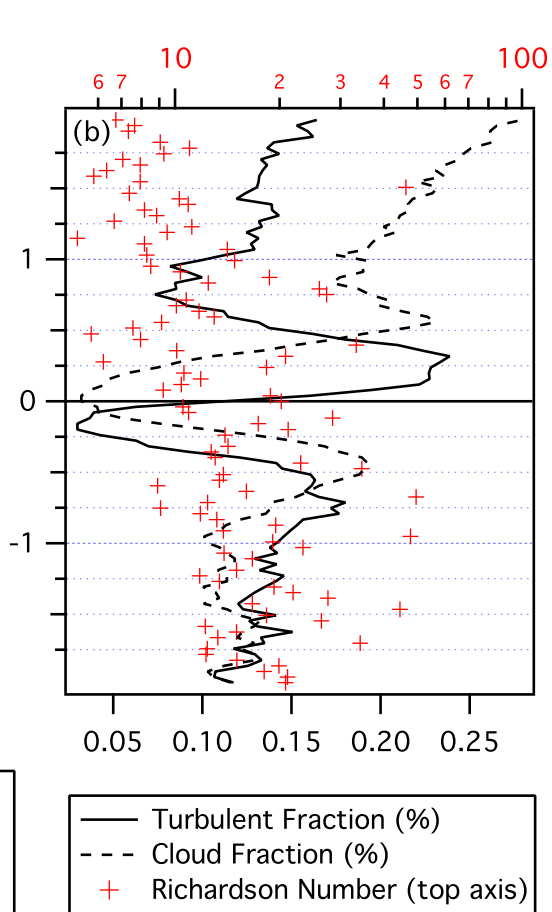
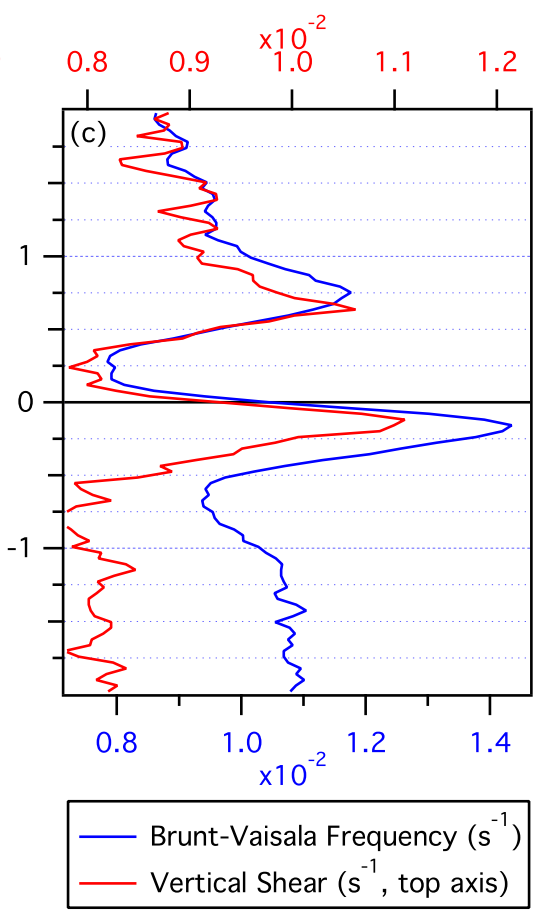

FIG. 8. Composites based on normalized temperature filtered perturbations $\left(T^{\prime} / T\right)_{f}$ of (a) unfiltered perturbations of zonal wind $u^{\prime}\left(\mathrm{m} \mathrm{s}{ }^{-1}\right.$; red solid), meridional wind $v^{\prime}$ ( $\mathrm{m} \mathrm{s}^{-1}$; red dashed), balloon ascent rate $w^{\prime}$ (multiplied by $5 ; \mathrm{m} \mathrm{s}^{-1}$; black), normalized temperature $T^{\prime} / T$ (green; upper axis), and specific humidity $q^{\prime}$ ( $\mathrm{g} \mathrm{kg}^{-1}$; blue); (b) raw turbulent fraction (black solid), cloud fraction (black dashed), and Richardson number (red crosses; upper axis); and (c) raw Brunt-Väisälä frequency $\left(\mathrm{s}^{-1}\right.$; blue) and vertical shear ( $\mathrm{s}^{-1}$; red; upper axis). Note that the vertical axis is in number of wavelengths. Perturbations are defined by removing a 5-day mean. Filtered perturbations are obtained by applying a low-pass filter removing wavelengths smaller than $1 \mathrm{~km}$ and removing a cubic fit and a 5-km boxcar (see section $2 \mathrm{c}$ for details).

Ascent rate perturbations, which are linked to vertical wind variations, have mean amplitude of less than $0.1 \mathrm{~m} \mathrm{~s}^{-1}$ and peak in between temperature and zonal wind perturbations. This suggests that the composites are indeed representative of GW activity (e.g., Holton 2004). Interestingly, these composites are associated with large variations in specific humidity. The observed moisture variations of about $0.5 \mathrm{~g} \mathrm{~kg}^{-1}$ are negatively correlated with temperature (and thus roughly in phase with density variations). These variations are primarily due to GW signal in the lower troposphere (mean amplitude of about $1 \mathrm{~g} \mathrm{~kg}^{-1}$, not shown), but such a signal is also observed in the upper troposphere with weaker amplitude (less than $0.1 \mathrm{~g} \mathrm{~kg}^{-1}$, not shown). Therefore, the moisture layers detected by Luce et al. (2010a) and Davison et al. $(2013 \mathrm{~b}, \mathrm{c})$ and the associated moisture gradients [Fig. 7b and Bellenger et al. (2015b)] could be partly associated with GW activity.

Figure $8 \mathrm{~b}$ shows the associated average profiles of turbulence percentage, cloud fraction, and Richardson number. There is a clear modulation of turbulence frequency (from less than $5 \%$ to close to $25 \%$ ) associated with these GWs and corresponding to small Richardson number. The turbulent fraction is in phase quadrature with temperature and moisture perturbations and in phase with zonal wind perturbations (Fig. 8a). Turbulence is associated with strongly negative vertical temperature gradients and strongly positive moisture gradients. This phase relationship between turbulence frequency and temperature perturbations is common for all altitudes, but the turbulence profile shows peak-topeak variations of slightly more than $10 \%$ in the lower troposphere and of about $30 \%$ in the upper troposphere (not shown). Interestingly, these GW perturbations are associated with a minimum in cloud fraction. Yet this fraction rises quickly above the turbulence maximum (especially in the lower troposphere), suggesting that turbulence often occurs near the cloud base, either for the stratiform extension of a convective system (Luce et al. 2010b), altocumulus (Wilson et al. 2014; Worthington 2015), or cirrus (Luce et al. 2010c).

To better understand the processes at work in turbulence generation by GWT with strong temperature signature, Fig. $8 \mathrm{c}$ shows the associated mean variation of the Brunt-Väisälä frequency and vertical shear of the horizontal wind. Both are negatively correlated with 

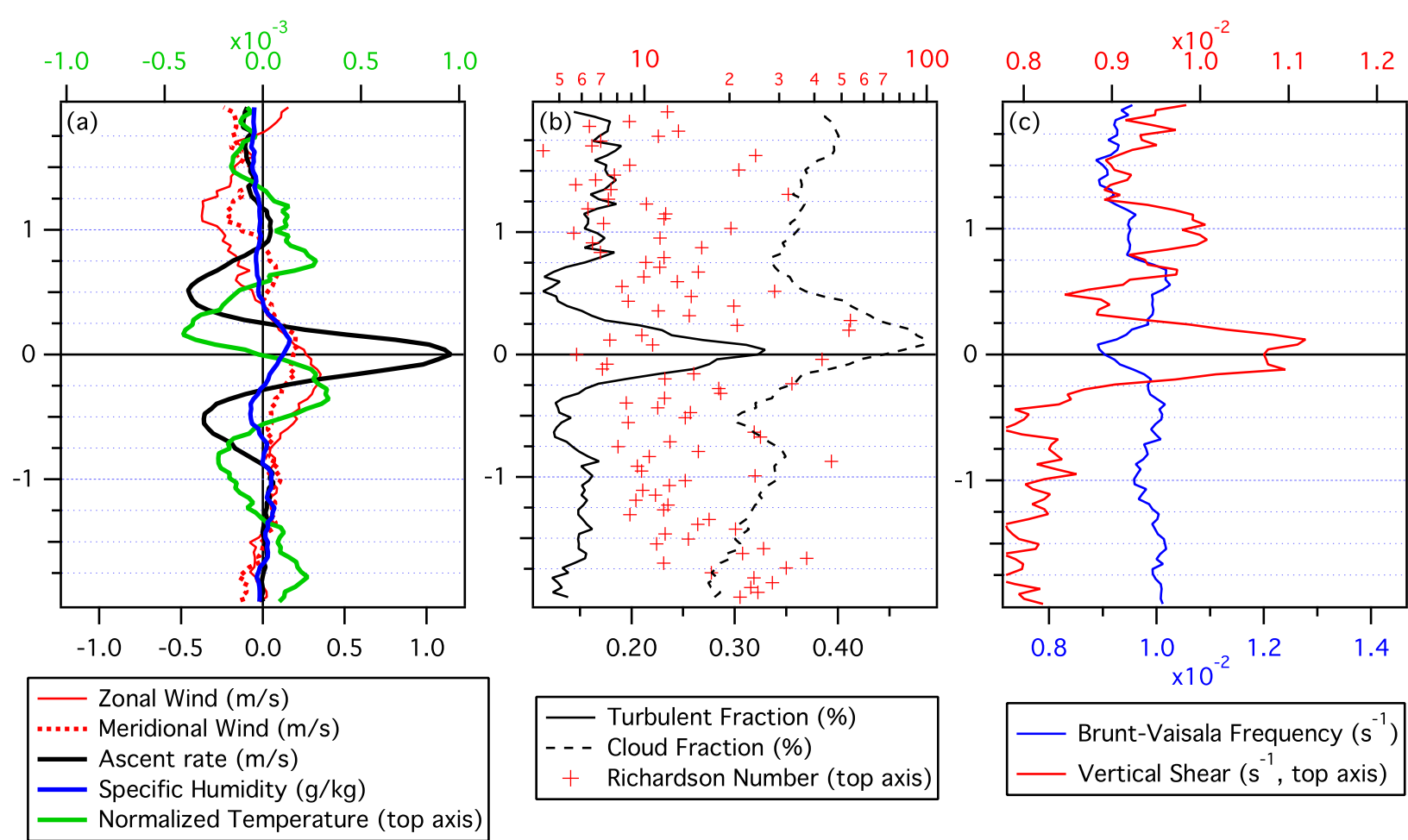

FIG. 9. As in Fig. 8, but with composites based on balloon vertical ascent rate filtered perturbations $w_{f}^{\prime}$.

turbulence frequency (Fig. 8b) with amplitudes on the order of $25 \%$ and $15 \%$ of their mean values, respectively. Turbulence is associated with a stability minimum, a wind speed maximum (Fig. 8a), and a vertical shear minimum (Fig. 8c). Maximum vertical shear values are found above and below, as in the case presented by Wilson et al. (2014). Note that this result does not guarantee that turbulence arises from the convective breaking of these GWTs (GWT-induced static instability). One reason is that the clear-air troposphere is statistically stable, and large temperature perturbations are thus needed to create unstable regions. This was not the case for previous studies considering the isothermal upper atmosphere (Hodges 1967; Chao and Schoeberl 1984; Fritts and Dunkerton 1985; Fritts et al. 1988b). Yet the change in stability associated with these waves may play a role in triggering turbulence. As discussed, for instance, by Worthington (2015), even if the temperature variation is not sufficient to induce convective instability and wave breaking, it can still reduce the stability enough so that even the average shear is sufficient to induce Kelvin-Helmholtz instability. This would be consistent with results from Fritts and Rastogi (1985) who found that lower frequency GWs are more likely to give rise to Kelvin-Helmoltz instability.

Figure 9a shows composites based on vertical ascent rate perturbations (black line). Corresponding apparent vertical wavelength and vertical position distributions are given in Fig. 10 (in black). Consistent with previous studies (Lane et al. 2003; Gong and Geller 2010; Hankinson et al. 2014b), GWws correspond to shorter vertical wavelengths (many events with $1-2-\mathrm{km}$ wavelengths) and thus higher frequencies (Fig. 10a). This confirms that the two GW ensembles, GWT and GWw, based on selection on temperature and ascent rate perturbation, respectively, are depicting different cases even if the two might not be entirely distinct. In contrast to the GWTs (green), these GWws tend to be more active in the upper troposphere (Fig. 10b). The composite on Fig. 9a shows large variation in ascent rate with an amplitude of $1.2 \mathrm{~ms}^{-1}$. The phase relationship between the ascent rate and the temperature variations is the same in Figs. 8a and 9a. Yet the signatures in horizontal wind and specific humidity are weaker. The weaker moisture perturbation can be partly explained by the relatively higher proportion of events diagnosed in the upper troposphere for GWws (60\%) compared to GWTs (35\%; see Fig. 10b). As in Fig. 8, maximum in turbulence (35\% due primarily to GWs in the upper troposphere, not shown) stands just below an increase cloud fraction and is associated with maximum ascent rate perturbation and with smaller Richardson number (Figs. 9a,b). Figure 9c shows that, for these higherfrequency GWs, maximum turbulence frequency is 
GW vertical wavelength \& altitude distributions using: Normalized Temperature (1077 cases) Ascent Speed (1294 cases)
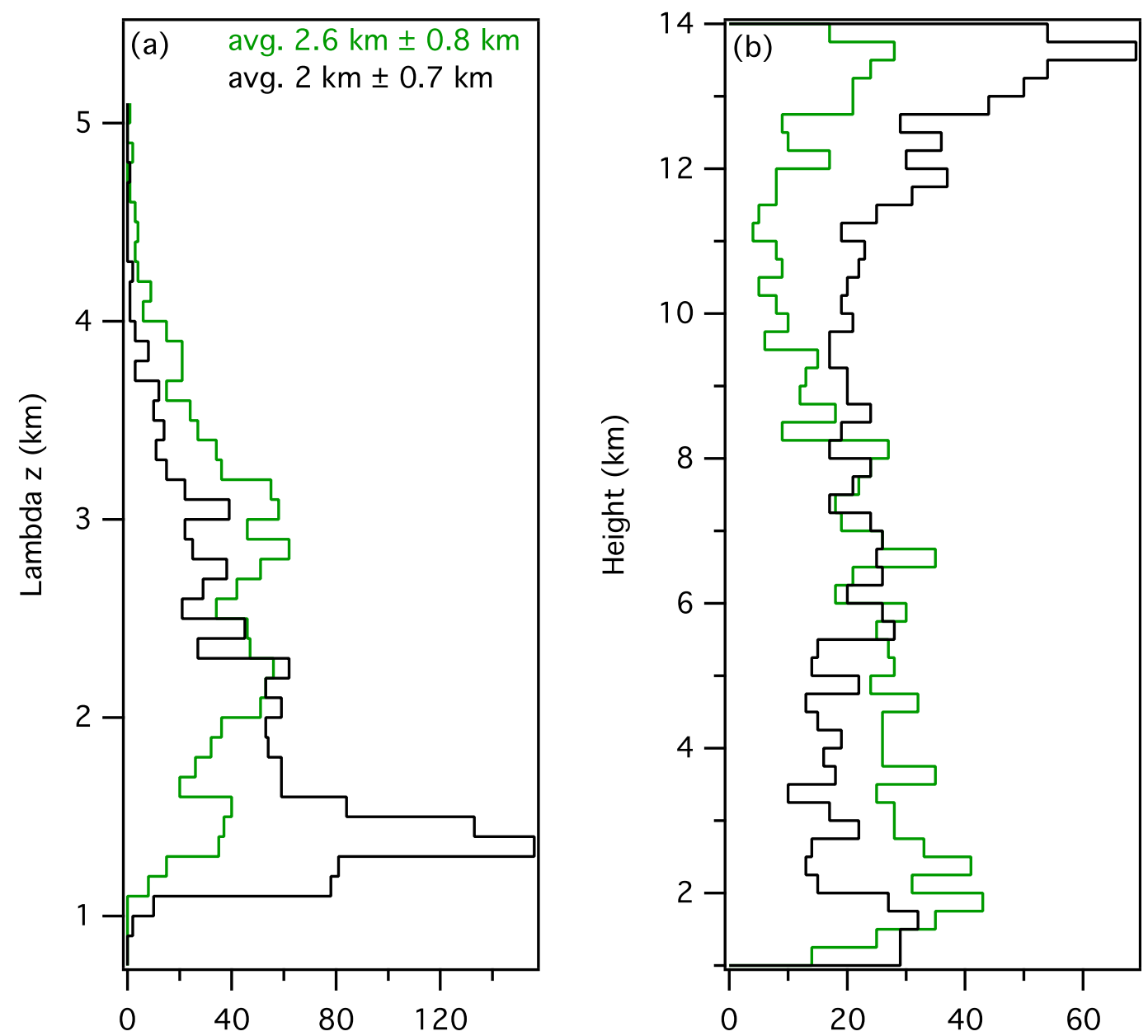

FIG. 10. Distributions of (a) vertical wavelengths for the GW cases selected on normalized temperature $\left(T^{\prime} / T\right)_{f}$ (green) and balloon ascent rate $w_{f}^{\prime}$ (black) used to construct composites in Figs. 8 and 9, respectively, and (b) the reference altitudes (corresponding to 0 on the Figs. 8 and 9 composite's vertical axis).

associated with maximum vertical shear and a decrease in static stability. This could reflect the fact that higherfrequency GWs tend to break because of both dynamical and convective instabilities, as shown by Fritts and Rastogi (1985). However, the decrease in static stability is weak $(\sim 10 \%)$, which suggest that turbulence is more likely to occur due to dynamical instability. In addition, one can note that these GWws have vertical wavelengths that are comparable to the vertical extent of observed Kelvin-Helmholtz billows $(\sim 1 \mathrm{~km}$ or more; see Luce et al. 2010c), which are also characterized by a strong signature in vertical wind.

Daily average indices of turbulence and GW activity (GWT based on normalized temperature and GWw based on vertical ascent) are computed for both the lower and upper troposphere. The only significant correlation is found in the lower troposphere between turbulence and GWT indices, where their activity is the strongest (Fig. 10b). When daily averages for both indices are computed using all eight 3-hourly radiosondes (168 days), the correlation is 0.66 . When at least four soundings per day can be used (337 days), the correlation is 0.52 . In the upper troposphere, no such relationship can be found, perhaps because of a greater role of other turbulence sources, such as evaporative cooling at cloud base (Luce et al. 2010c; Wilson et al. 2014), given that clouds are more frequent at these altitudes (e.g., Figs. 2c, 7a).

Finally, note that when constructing our composites on zonal wind perturbations (GWus), we obtain structures 
that are consistent with the classical view of GWs, similar to what is seen in Fig. 8a (not shown). Furthermore, these GWus are characterized by larger vertical wavelength, ranging from 2 to $4 \mathrm{~km}$ with a clear peak at about $3 \mathrm{~km}$, as predicted by Lane et al. (2003). They are primarily observed in the upper troposphere (not shown). Yet the associated turbulent fraction variations are weaker $(\sim 5 \%)$. This suggests that either these low-frequency GWus do not usually break in the troposphere or that the localization of turbulence in a particular phase of these waves is very weak.

\section{Link with the tropical variability}

The focus of this section is the link between GWTs and GWws juxtaposed with local and regional convective activity. However, it should be noted that other sources, such as the jet stream, might have an influence on GW activity, even in this region of the equatorial Indian Ocean. Previous studies already reported higherfrequency/shorter-vertical-wavelength GWs in the direct environs of convective clouds (e.g., Lane et al. 2003; Gong and Geller 2010; Dhaka et al. 2011; Hankinson et al. 2014b). The present dataset differs from these previous ones, since it represents an open-ocean environment far away from any significant topography. Figure 11 shows scatterplots of daily GW activity indices (GWT based on temperature and GWw on vertical ascent rate) in the lower and upper troposphere as a function of the C-band radar-derived daily average echo-top height for $\mathrm{C} / \mathrm{D}$ observation sites (Xu et al. 2015). It is clear that GWTs characterized by a strong signal in temperature are negatively correlated to local convective activity in both the lower troposphere (Fig. 11c) and in the upper troposphere, although the correlation is not significant (Fig. 11a). This is possibly because these longer-wavelength GWs can travel farther away from their source in a stable environment and thus are more active in calm regions away from convective sources. These waves could also be associated with frontal structures, for example, because of intrusions of dry air into the ITCZ, which are observed in this region (Kerns and Chen 2014). In contrast, short GWws are positively correlated with local convection (Figs. 11b,d) with a higher correlation coefficient in the upper troposphere. This is consistent with previous studies, such as Dhaka et al. (2011), which showed shorter-wavelength GWs in the upper troposphere as being associated with local convection. This is also consistent with observations reported by Hankinson et al. (2014b), although they focus on stratospheric GWs at higher altitudes. Thus, depending on convective activity, the characteristics of GWs change with more GWs having larger vertical wavelengths (within the $1-5-\mathrm{km}$ band) during suppressed conditions and shorter ones during active convection.

The link between turbulence and moisture in the lower troposphere that is visible on Fig. 7a has also been discussed in Bellenger et al. (2015b). The dry intrusion over Gan Island on 30 November described by Kerns and Chen (2014) is the beginning of a long period of dry conditions over the equator that lasts throughout December and January (Fig. 7a). Figure 12a shows the distribution of lower-tropospheric moisture and the threshold used to define dry and wet conditions (time series reported on Fig. 7a). Figure 12 further shows the sensitivity of GW activity and turbulence characteristics to this criterion in the lower troposphere. The activity of GWTs is greater in dry conditions (Fig. 12b), whereas the opposite is observed for the shorter GWws (Fig. 12c). This is consistent with long GWTs found in stable environments associated with dry conditions and with short GWws directly linked to local convective activity. Finally, turbulence is stronger during dry conditions compared to wet conditions (Fig. 12d). Note that these results are tightly linked to Fig. 11, as the driest conditions correspond to low convective activity, whereas humid ones correspond to more convection.

Tropical depressions (TD) and cyclones are associated with organized convective systems that are wellknown sources of inertia-GWs (e.g., Ki and Chun 2010). Figure 13 is a simple diagnostic showing the distributions of the standard deviation of normalized temperature perturbations (the GWT activity index) depending on the presence (or lack) of TDs close to the observation sites (as defined by the gray frame on Fig. 1). The time series of this TD index is also reported on Fig. 7a (gray bars on the top) together with other indices. TDs are present during any phase of the MJO in this example. Yet a more precise analysis reveals that the MJO does indeed modulate the number of TD initiations (Duvel 2015). Clearly, GWT activity increases when a TD is present in the vicinity. No such difference is noted on GWw activity. This does not prove that the increase of GWT activity is only related to TDs, since GWT may have other sources (such as fronts or jet streams), but this stresses that a variety of nonlocal sources of GWTs may have to be taken into account to correctly trace the source(s) of turbulence.

As local and surrounding convection can affect turbulent generation through modulation of GW activity, large-scale climate phenomena such as the MJO should also have an impact on turbulence occurrence and origin over the Indian Ocean. Considering the observation sites' locations (Fig. 1), MJO phases 1-4 correspond to convectively active periods and phases 
Upper Troposphere (7 - $15 \mathrm{~km})$
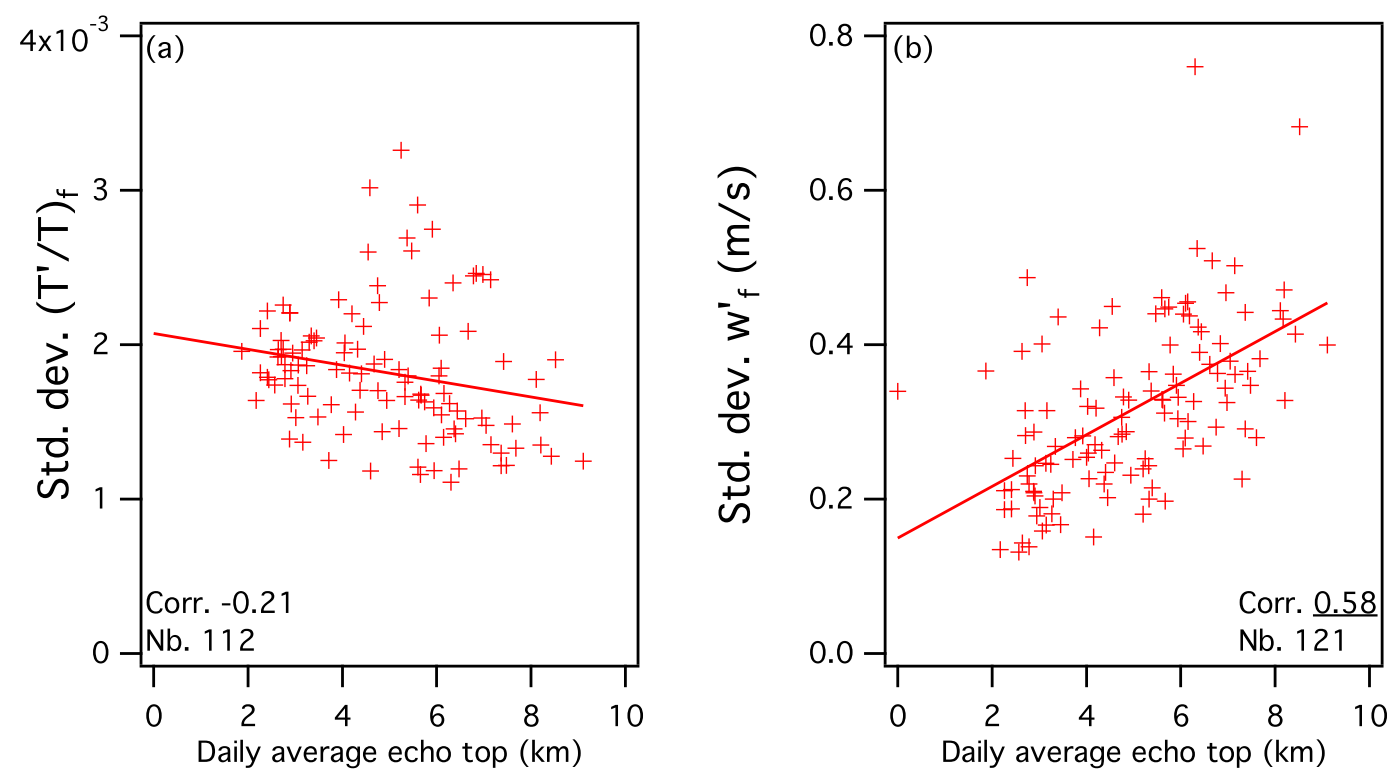

Lower Troposphere $(1-7 \mathrm{~km})$
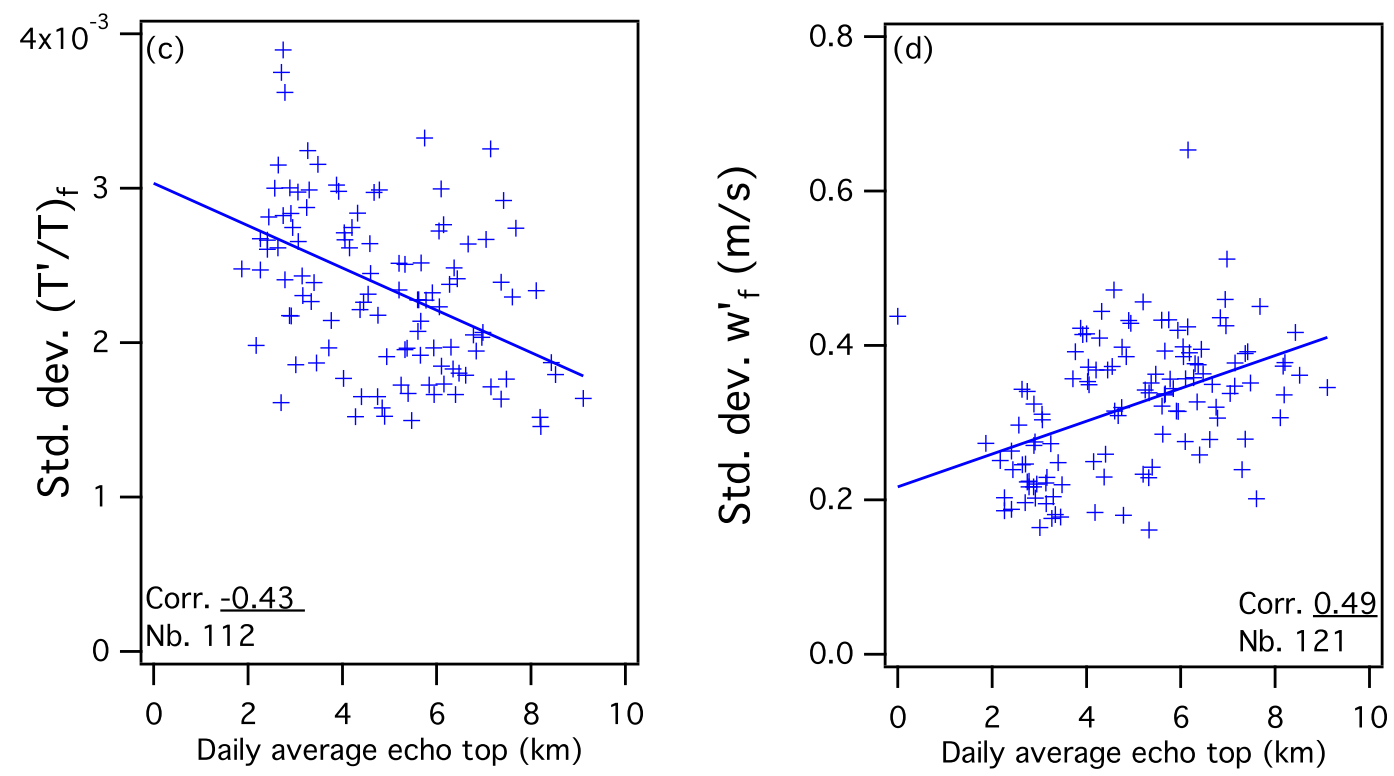

FIG. 11. Scatterplots of daily (a),(c) GWT and (b),(d) GWw activity indices (filtered perturbation standard deviation for normalized temperature and vertical ascent rate, respectively) for the upper (red) and lower (blue) troposphere as a function of daily average echo top observed during C/D from Gan, R/V Mirai, and R/V Revelle (Xu et al. 2015, their Fig. 7). The daily GW activity indices are computed only using days with eight values of GW. Linear correlation coefficients and the numbers of days used for the computation are also indicated. Underlined correlation coefficients are significant at the $99 \%$ level.

5-8 to suppressed periods (Wheeler and Hendon 2004). Indeed, dry conditions are usually observed during phase 5-8 of the MJO over Gan Island (Fig. 7a). Figure 14 shows the degree of activity of long GWTs and short GWws and of turbulence in the lower and upper troposphere as a function of MJO phase. In both the lower and upper troposphere, GWTs are the most sensitive to MJO phase with maximum activity during phases 4-7 (Fig. 14a), when convection moves east away from the observation sites in the Indian Ocean 

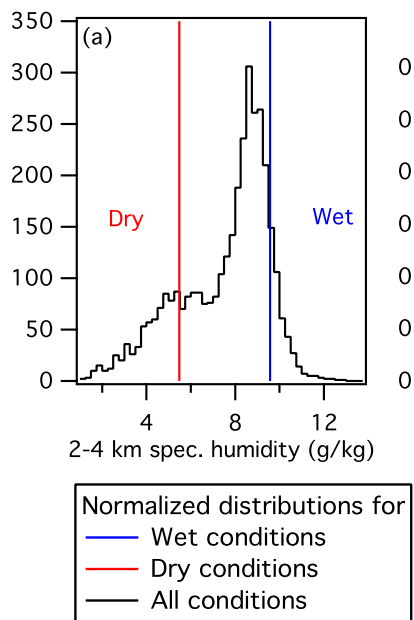

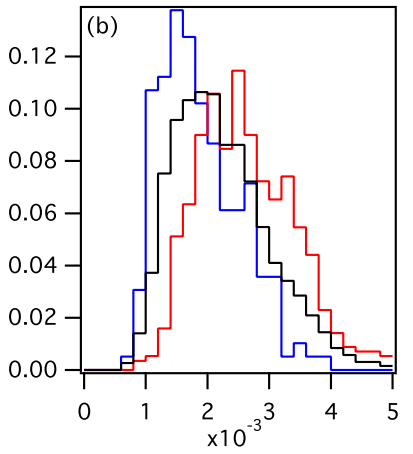

Std. dev. $\left(T^{\prime} / T\right)_{f}$

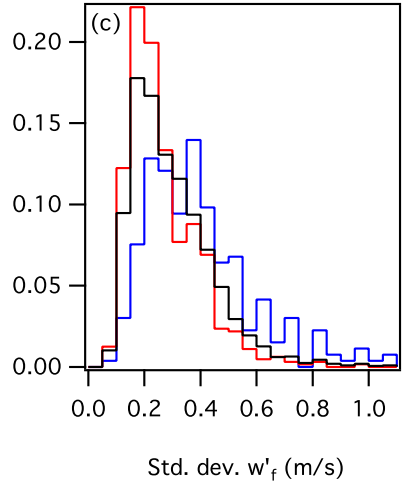

Std. dev. $w_{f}^{\prime}(m / s)$

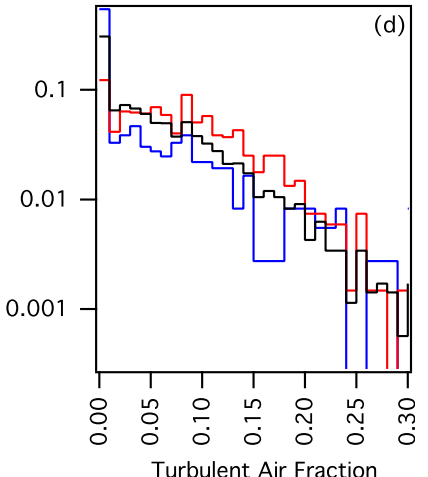

Turbulent Air Fraction

FIG. 12. (a) Frequency of occurrence of the mean 2-4-km-height mixing ratio $\left(\mathrm{g} \mathrm{kg}^{-1}\right)$ for the entire dataset together with the threshold to define dry (red) and wet (blue) conditions (vertical lines). Normalized distributions of the (b) GWT activity index and (c) GWw activity index and (d) the turbulent fraction in the lower troposphere. Red and blue distributions correspond to dry and wet conditions, respectively. The black distribution corresponds to all conditions. GWT (GWw) activity is measured by the standard deviation of normalized temperature (balloon ascent rate) filtered perturbations. In (b),(c), and (d), the blue and red distributions are found significantly different to the $99 \%$ level by using a $\chi^{2}$ two-sample test.

[see Fig. 1 and Wheeler and Hendon (2004)]. Short GWws have maximum activity in the upper troposphere during phases 2-6 (Fig. 14b), corresponding to both active and suppressed phases of the MJO. Turbulent fraction variation with $\mathrm{MJO}$ phase is also evident in the lower and upper troposphere (Fig. 14c). Turbulent fraction peaks during phase 6 (dry conditions) in the former case and during phase 3 (convective conditions) in the latter case, although it is difficult to simply attribute these peaks to maxima in GWT and GWw activity.

\section{Summary and discussion}

This article presents a statistical analysis of tropospheric turbulence in a tropical open-ocean region based on a large dataset of radiosondes (more than 3500 soundings from the MISMO, CIRENE, and C/D

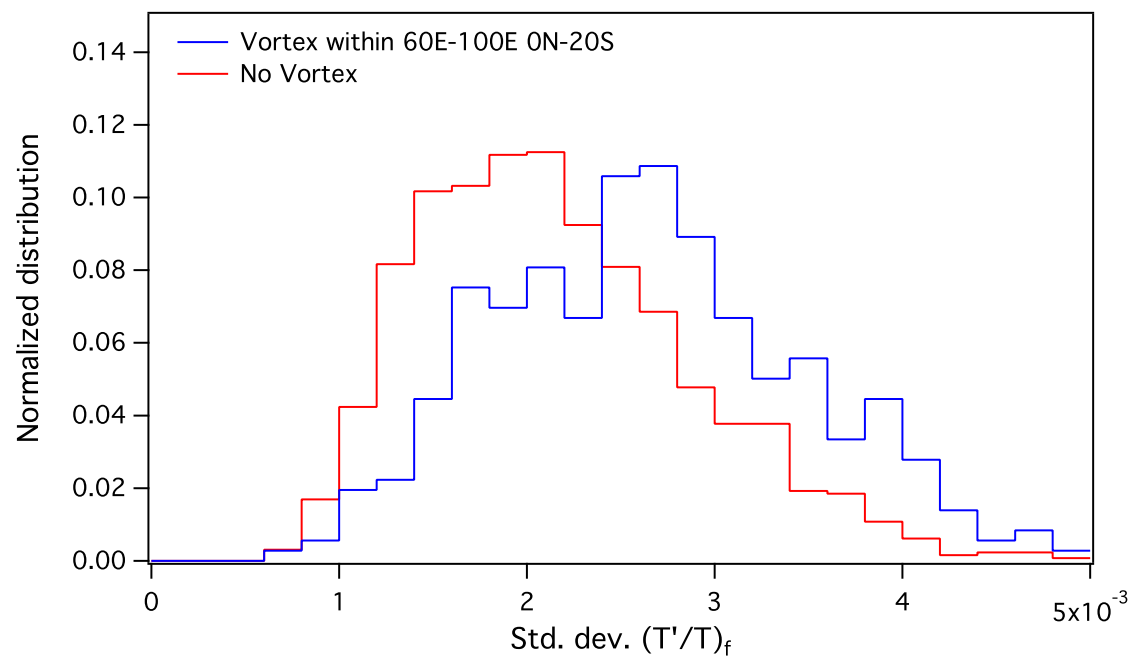

FIG. 13. Normalized distributions of GWT activity in the lower troposphere (1-7 km) when a vortex is present in $20^{\circ} \mathrm{S}-0^{\circ}, 60^{\circ}-100^{\circ} \mathrm{E}$ (blue) or absent (red). Vortices are selected following Duvel (2015). GWT activity is measured by the standard deviation of normalized temperature filtered perturbations. The two distributions are significantly different to the $99 \%$ level using a $\chi^{2}$ two-sample test. 

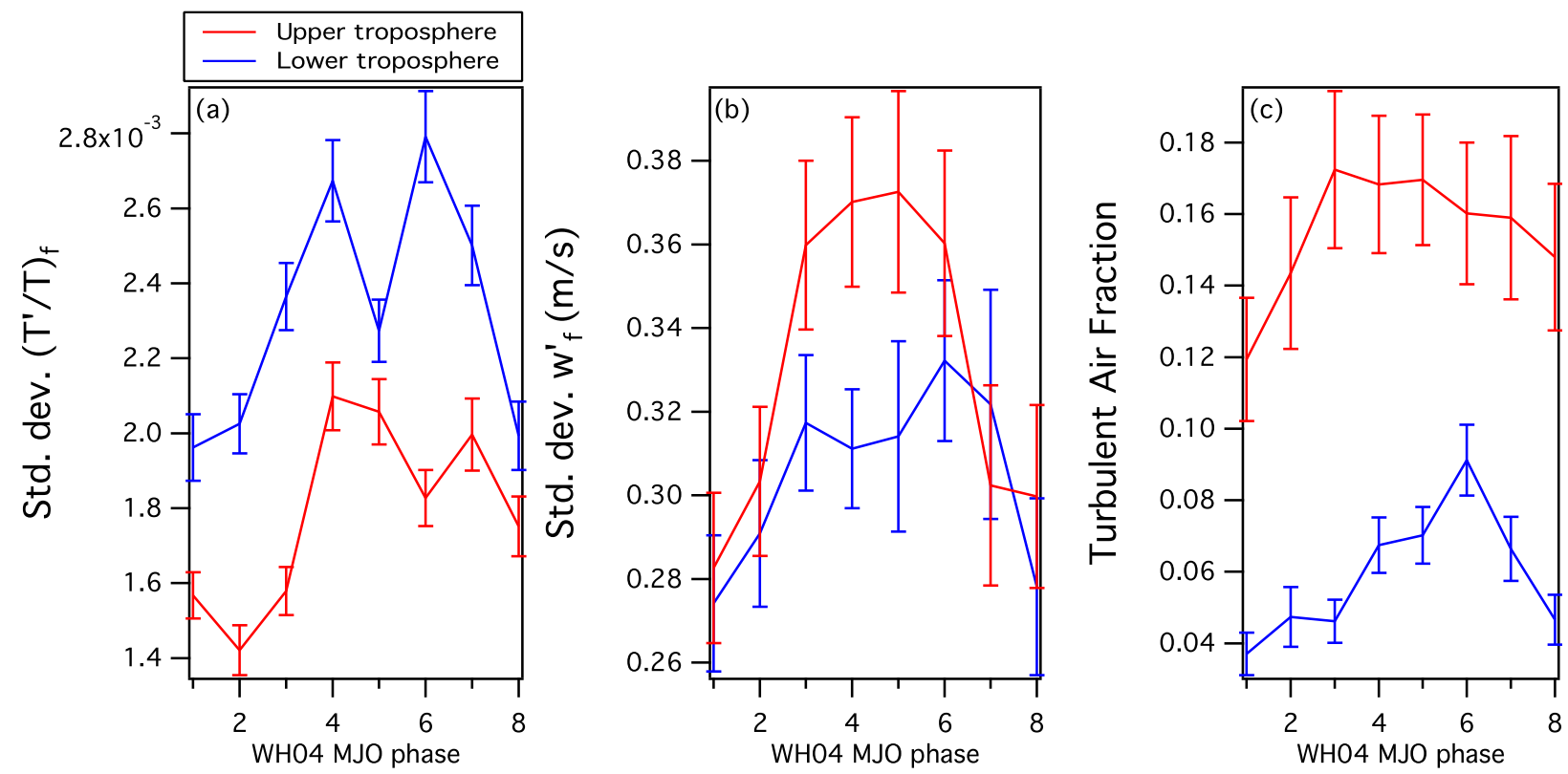

FIG. 14. Mean (a) GWT and (b) GWw activity and (c) turbulent fraction as a function of the Wheeler and Hendon (2004) RMM index MJO phase (for index amplitude higher than 1). GWT (GWw) activity is measured by the standard deviation of normalized temperature (balloon ascent rate) filtered perturbations. Red (blue) is for upper (lower) troposphere. Error bars represent the $t$-based $99 \%$ confidence interval for the means.

campaigns), which confirm and extend the study of Bellenger et al. (2015b). Turbulent regions extending from 40 to $1000 \mathrm{~m}$ in the vertical are observed, corresponding to eddy diffusivities on the order of $1-100 \mathrm{~m}^{2} \mathrm{~s}^{-1}$. These values are obtained making some assumptions about the link between the Thorpe and the Ozmidov length scales (e.g., Schneider et al. 2015; Fritts et al. 2016). We note that Thorpe analysis based on regular radiosondes may miss the smallest turbulent regions, while potentially creating unrealistically large regions by merging neighboring small ones (Wilson et al. 2013). Part of the largest turbulent regions detected here may result from several smaller overturns, leading us to believe the tail of the distribution is overestimated. Turbulence is most frequent in the upper free troposphere near 12-km height, with larger vertical extents than those in the lower troposphere. Yet, because of the relatively lower stability in the upper troposphere, eddy diffusivities are comparable in both domains. Furthermore, turbulence clearly corresponds locally to weaker stability than for the surrounding environment but not to stronger vertical shear. This suggests a role for GWs in the creation of turbulence based on past theoretical works (Hodges 1967; Chao and Schoeberl 1984; Fritts and Dunkerton 1985) and observations (Fritts and Rastogi 1985; Fritts et al. 1988b).

The link between turbulence and GWs is then further investigated. The GW signals with apparent vertical wavelengths of $1-5 \mathrm{~km}$ are detected in the filtered perturbations of horizontal wind, temperature, and balloon vertical ascent profiles. Composites are constructed based on strong variations in each of these parameters that correspond well to GW structure. Consistent with Lane et al. (2003) and Geller and Gong (2010), horizontal wind variations are associated with larger apparent GW vertical wavelengths, ascent rate with shorter ones, and temperature in between. While no clear link such as spatial phase locking is found between turbulence and GWs isolated from their signature in horizontal wind, there is however a clear modulation of turbulence occurrence by GWs with strong signal in temperature and vertical ascent rate. The former are mainly detected in the lower troposphere, whereas the latter are mainly detected in the upper troposphere.

Some notable differences in the link between turbulence and GWs are found for short GWws and long GWTs. For GWTs, turbulence appears in conjunction with negative GW anomalies in the temperature gradient (a decrease in stability) and with maximum horizontal wind (a minimum in vertical shear), as predicted by theory (Hodges 1967; Chao and Schoeberl 1984; Fritts and Dunkerton 1985) and observed in cases studies (Fritts et al. 1988b; Wilson et al. 2014). Turbulence may thus sometimes result from convective instability alone, but, more generally, both stability reduction by the GWs and vertical shear may generate 
turbulence. In other words, the GWs reduce the stability so that any shear is sufficient to create dynamic instability (e.g., Worthington 2015). For short GWws, turbulence appears collocated with vertical ascent rate, a slight minimum in stability, and a clear maximum vertical shear, suggesting a more direct role for dynamic instability. In both composites, the cloud base appears above the turbulent level. This suggests that other processes, such as the evaporative cooling at the cloud base could also be important for turbulence generation.

The tight link between turbulence and GWs sheds some light on the observed temporal variations of turbulence. Short GWws are associated with local convection, consistent with previous findings (Lane et al. 2003; Dhaka et al. 2011; Hankinson et al. 2014b). Conversely, longer GWs are more active during dry and suppressed convective activity especially in the lower troposphere, where they propagate far from their sources or are locally emitted, for instance, by fronts linked to dry-air intrusions (Kerns and Chen 2014). A link is indeed found between this GW activity and the presence of organized convection, such as tropical depressions or cyclones in the basin or during the suppressed phase of the MJO. This provides an explanation for the observed turbulence increase in the lower troposphere during the most stable periods. It has to be noted, however, that the impact of this GW-induced turbulence on the increase of low-level moisture during this suppressed period is still uncertain and depends on parameters that are difficult to constrain experimentally (Bellenger et al. 2015b; Schneider et al. 2015).

An interesting outcome from this study is the link between GWs, turbulence, and moisture vertical profiles. This link should be further investigated, as it suggests the role of GWs and their associated turbulence in the observed sheets and layers structures recently reported in the free troposphere (Luce et al. 2010a; Davison et al. 2013b,c; Davison 2015; Fritts et al. 2016). In this study, we concentrate on the link between turbulence and GWs, although there can be other sources of turbulence, such as evaporative cooling at cloud base (Luce et al. 2010c; Wilson et al. 2014). A large part of the atmospheric turbulence is also associated with the static stability reduction by condensation inside clouds (Wilson et al. 2013; Worthington 2015). This should be carefully taken into account by separating convective and nonconvective cloudy portions of the soundings profiles for the whole dataset. This is certainly necessary to offer a full picture of turbulence in the troposphere and assess its impact on the formation of sheets and layers structures (Luce et al. 2010a; Davison et al. 2013a,b,c; Davison 2015; Fritts et al. 2016) and on vertical moisture transport (Bellenger et al. 2015b). Finally, the diurnal variability of turbulence occurrence in the upper troposphere
(Lane et al. 2003; Hankinson et al. 2014b; Liu et al. 2014) and its origin remain to be studied.

Acknowledgments. The authors thank H. Luce and K. Yoneyama for insightful comments and suggestions. J. L. Davison is supported by NSF Award 1331291. The authors also thank J. Vialard for discussions and making CIRENE data available, Captain Y. Ishioka, his crew, and technical staff of Global Ocean Development, Inc., for their support of observations onboard R/V Mirai during MISMO and C/D cruises. Finally, the authors acknowledge the editor and the anonymous reviewers for greatly helping to improve this manuscript. The data used in this study are available online: (http://www.jamstec.go.jp/iorgc/mismo/index-e.html; http:// campagnes.flotteoceanographique.fr/campagnes/7020010/; and http://www.jamstec.go.jp/iorgc/cindy/obs/obs.html).

\section{REFERENCES}

Alappattu, D. P., and P. K. Kunhikrishnan, 2010: First observations of turbulence parameters in the troposphere over the Bay of Bengal and the Arabian Sea using radiosonde. J. Geophys. Res., 115, D06105, doi:10.1029/2009JD012916.

Balsley, B. B., G. Svensson, and M. Tjernström, 2008: On the scale-dependence of the gradient Richardson number in the residual layer. Bound.-Layer Meteor., 127, 57-72, doi:10.1007/s10546-007-9251-0.

_ L. Kantha, and W. Colgan, 2010: On the use of Slow Ascent Meter-Scale Sampling (SAMS) Radiosondes for observing overturning events in the free atmosphere. J. Atmos. Oceanic Technol., 27, 766-775, doi:10.1175/2009JTECHA1310.1.

Barat, J., 1983: The fine structure of the stratospheric flow revealed by differential sounding. J. Geophys. Res., 88, 5219-5228, doi:10.1029/JC088iC09p05219.

Bellenger, H., and J. P. Duvel, 2012: The event-to-event variability of the boreal winter MJO. Geophys. Res. Lett., 39, L08701, doi:10.1029/2012GL051294.

_ - Y. N. Takayabu, T. Ushiyama, and K. Yoneyama, 2010: Role of diurnal warm layers in the diurnal cycle of convection over the tropical Indian Ocean during MISMO. Mon. Wea. Rev., 138, 2426-2433, doi:10.1175/2010MWR3249.1.

_- K. Yoneyama, M. Katsumata, T. Nishizawa, K. Yasunaga, and R. Shirooka, 2015a: Observation of moisture tendencies related to shallow convection. J. Atmos. Res., 72, 641-659, doi:10.1175/JAS-D-14-0042.1.

_- M. Katsumata, and K. Yoneyama, 2015b: Turbulent mixing and its impact on lower tropospheric moisture over tropical ocean. Geophys. Res. Lett., 42, 3030-3037, doi:10.1002/ 2015 GL063868.

Benedict, J. J., and D. A. Randall, 2007: Observed characteristics of the MJO relative to maximum rainfall. J. Atmos. Sci., 64, 2332-2354, doi:10.1175/JAS3968.1.

Cadet, D., 1977: Energy dissipation within intermittent clear air turbulence patches. J. Atmos. Sci., 34, 137-142, doi:10.1175/ 1520-0469(1977)034<0137:EDWICA>2.0.CO;2.

Chao, W. C., and M. R. Schoeberl, 1984: On the linear approximation of gravity wave saturation in the mesosphere. J. Atmos. Sci., 41, 1893-1898, doi:10.1175/1520-0469(1984) 041<1893:OTLAOG > 2.0.CO;2. 
Cho, J. Y. N., R. E. Newell, B. E. Anderson, J. D. W. Barrick, and K. L. Thornhill, 2003: Characterizations of tropospheric turbulence and stability layers from aircraft observations. J. Geophys. Res., 108, 8784, doi:10.1029/2002JD002820.

Ciesielski, P. E., and Coauthors, 2014: Quality-controlled upper-air sounding dataset for DYNAMO/CINDY/AMIE: Development and corrections. J. Atmos. Oceanic Technol., 31, 741764, doi:10.1175/JTECH-D-13-00165.1.

Clayson, C. A., and L. Kantha, 2008: On turbulence and mixing in the free atmosphere inferred from high-resolution soundings. J. Atmos. Oceanic Technol., 25, 833-852, doi:10.1175/ 2007JTECHA992.1.

Davison, J. L., 2014: Investigation of the island effect on mixed layer top and transition layer top elevations using Bragg Scattering Layer (BSL) analysis of clear-air S-Pol radar retrievals at the Gan site during CINDY2011/DYNAMO/AMIE. 31st Conf. on Hurricanes and Tropical Meteorology, San Diego, CA, Amer. Meteor. Soc., 6B.1. [Available online at https://ams.confex.com/ ams/31Hurr/webprogram/Paper243993.html.]

- 2015: A filter for removing sidelobe artifacts in Bragg scattering layer (BSL) analysis for S-band radar. J. Atmos. Oceanic Technol., 32, 1289-1297, doi:10.1175/JTECH-D-15-0033.1.

— , R. M. Rauber, L. Di Girolamo, and M. A. LeMone, 2013a: A revised conceptual model of the tropical marine boundary layer. Part I: Statistical characterization of the variability inherent in the wintertime trade wind regime over the western tropical Atlantic J. Atmos. Sci., 70, 3025-3046, doi:10.1175/JAS-D-12-0321.1.

,$- \ldots$, and,$- 2013 \mathrm{~b}$ : A revised conceptual model of the tropical marine boundary layer. Part II: Detecting relative humidity layers using Bragg scattering from S-band radar. J. Atmos. Sci., 70, 3025-3046, doi:10.1175/JAS-D-12-0322.1.

,,--- , and M. A. LeMone, 2013c: A revised conceptual model of the tropical marine boundary layer. Part III: Bragg scattering layer statistical properties. J. Atmos. Sci., 70, 30473062, doi:10.1175/JAS-D-12-0323.1.

Dewan, E. M., 1981: Turbulent vertical transport due to thin intermittent mixing layers in the stratosphere and other stable fluids. Science, 211, 1041-1042, doi:10.1126/ science.211.4486.1041.

Dhaka, S. K., R. Bhatnagar, Y. Shibagaki, H. Hashiguchi, S. Fukao, T. Kozu, and V. Panwar, 2011: Characteristics of gravity waves generated in a convective and a non-convective environment revealed from hourly radiosonde observation under CPEA-II campaign. Ann. Geophys., 29, 2259-2276, doi:10.5194/ angeo-29-2259-2011.

Duvel, J.-P., 2015: Initiation and intensification of tropical depressions over the southern Indian Ocean: Influence of the MJO. Mon. Wea. Rev., 143, 2170-2191, doi:10.1175/ MWR-D-14-00318.1.

- C. Basdevant, H. Bellenger, G. Reverdin, A. Vargas, and J. Vialard, 2009: The Aeroclipper: A new device to explore convective systems and cyclones. Bull. Amer. Meteor. Soc., 90, 63-71, doi:10.1175/2008BAMS2500.1.

Feng, Z., S. A. McFarlane, C. Schumacher, S. Ellis, J. Comstock, and N. Bharadwaj, 2014: Constructing a merged cloudprecipitation radar dataset for tropical convective clouds during the DYNAMO/AMIE experiment at Addu Atoll. J. Atmos. Oceanic Technol., 31, 1021-1042, doi:10.1175/ JTECH-D-13-00132.1.

Fritts, D. C., and T. J. Dunkerton, 1985: Fluxes of heat and constituents due to convectively unstable gravity waves. J. Atmos. Sci., 42, 549-556, doi:10.1175/1520-0469(1985)042<0549: FOHACD $>2.0 . \mathrm{CO} ; 2$.
— due to gravity wave motions in the lower and middle atmosphere: Theory and observations. Radio Sci., 20, 1247-1277, doi:10.1029/ RS020i006p01247.

, T. Tsuda, T. Sato, S. Fukao, and S. Kato, 1988a: Observational evidence of a saturated gravity wave spectrum in the troposphere and lower stratosphere. J. Atmos. Sci., 45, 1741-1759, doi:10.1175/1520-0469(1988)045<1741:OEOASG >2.0.CO;2.

— S. A. Smith, B. B. Balsley, and C. R. Philbrick, 1988b: Evidence of gravity wave saturation and local turbulence production in the summer mesosphere and lower thermosphere during the STATE experiment. J. Geophys. Res., 93, 7015-7025, doi:10.1029/ JD093iD06p07015.

- L. Wang, M. A. Geller, D. A. Lawrence, J. Werne, and B. B. Balsley, 2016: Numerical modeling of multiscale dynamics at a high Reynolds number: Instabilities, turbulence, and an assessment of Ozmidov and Thorpe scales. J. Atmos. Sci., 73, 555-578, doi:10.1175/JAS-D-14-0343.1.

Gallice, A., F. G. Wienhold, C. R. Hoyle, F. Immler, and T. Peter, 2011: Modeling the ascent of sounding balloons: Derivation of the vertical air motion. Atmos. Meas. Tech., 4, 2235-2253, doi:10.5194/amt-4-2235-2011.

Gavrilov, N. M., H. Luce, M. Crochet, F. Dalaudier, and S. Fukao, 2005: Turbulence parameter estimations from high-resolution balloon temperature measurements of the MUTSI-2000 campaign. Ann. Geophys., 23, 2401-2413, doi:10.5194/ angeo-23-2401-2005.

Geller, M. A., and J. Gong, 2010: Gravity wave kinetic, potential, and vertical fluctuation energies as indicators of different frequency gravity waves. J. Geophys. Res., 115, D11111, doi:10.1029/ 2009JD012266

Gong, J., and M. A. Geller, 2010: Vertical fluctuation energy in United States high vertical resolution radiosondes data as an indicator of convective gravity wave sources. J. Geophys. Res., 115, D11110, doi:10.1029/2009JD012265.

Hankinson, M. C. N., M. J. Reeder, and T. P. Lane, 2014a: Gravity waves generated by convection during TWP-ICE: 1 . Inertiagravity waves. J. Geophys. Res. Atmos., 119, 5269-5282, doi:10.1002/2013JD020724.

,-- , and $-2014 \mathrm{~b}$ : Gravity waves generated by convection during TWP-ICE: 2. High-frequency gravity waves. J. Geophys. Res. Atmos., 119, 5357-5268, doi:10.1002/ 2013JD020726.

Hodges, R. R., Jr., 1967: Generation of turbulence in the upper atmosphere by internal gravity waves. J. Geophys. Res., 72, 3455-3458, doi:10.1029/JZ072i013p03455.

Holloway, C. E., and J. D. Neelin, 2009: Moisture vertical structure, column water vapor, and tropical deep convection. J. Atmos. Sci., 66, 1665-1683, doi:10.1175/2008JAS2806.1.

Holton, J. R., 2004: An Introduction to Dynamical Meteorology. 4th ed. International Geophysics Series, Vol. 88, Academic Press, $535 \mathrm{pp}$.

Jensen, M. P., and A. D. Del Genio, 2006: Factors limiting convective cloud-top height at the ARM Nauru Island climate facility. J. Climate, 19, 2105-2117, doi:10.1175/JCLI3722.1.

Johnson, R. H., P. E. Ciesielski, and J. A. Cotturone, 2001: Multiscale variability of the atmospheric mixed layer over the western Pacific warm pool. J. Atmos. Sci., 58, 2729-2750, doi:10.1175/ 1520-0469(2001)058<2729:MVOTAM>2.0.CO;2.

Kantha, L., and W. Hocking, 2011: Dissipation rates of turbulence kinetic energy in the free atmosphere: MST radar and radiosondes. J. Atmos. Sol.-Terr. Phys., 73, 1043-1051, doi:10.1016/ j.jastp.2010.11.024. 
Karoly, D. J., G. L. Roff, and M. J. Reeder, 1996: Gravity wave activity associated with tropical convection detected in TOGA COARE sounding data. Geophys. Res. Lett., 23, 261-264, doi:10.1029/96GL00023.

Katsumata, M., T. Ushiyama, K. Yoneyama, and Y. Fujiyoshi, 2008: Combined use of TRMM/PR and disdrometer data to correct reflectivity of ground-based radars. SOLA, 4, 101-104, doi:10.2151/sola.2008-026.

Kerns, B. W., and S. S. Chen, 2014: Equatorial dry air intrusion and related synoptic variability in $\mathrm{MJO}$ initiation during DYNAMO. Mon. Wea. Rev., 142, 1326-1343, doi:10.1175/ MWR-D-13-00159.1.

Ki, M.-O., and H.-Y. Chun, 2010: Characteristics and sources of inertia-gravity waves revealed in the KEOP-2007 radiosonde data. Asia-Pac. J. Atmos. Sci., 46, 261-277, doi:10.1007/ s13143-010-1001-4.

Lane, T. P., M. J. Reeder, and F. M. Guest, 2003: Convectively generated gravity waves observed from radiosonde data taken during MCTEX. Quart. J. Roy. Meteor. Soc., 129, 1731-1740, doi:10.1256/qj.02.196.

Leena, P. P., M. Venkat Ratman, and B. V. Krishna Murthy, 2012: Inertia gravity wave characteristics and associated fluxes observed using five years of radiosonde measurements over a tropical station. J. Atmos. Sol.-Terr. Phys., 84-85, 37-44, doi:10.1016/j.jastp.2012.05.004.

Liu, X., J. Y. Xu, and W. Yuan, 2014: Diurnal variations of turbulence parameters over the tropical oceanic upper troposphere during SCSMEX. Sci. China Technol. Sci., 57, 351-359, doi:10.1007/s11431-013-5445-5.

Luce, H., S. Fukao, F. Dalaudier, and M. Crochet, 2002: Strong mixing events observed near the tropopause with the MU radar and high-resolution balloon techniques. J. Atmos. Sci., 59, 2885-2896, doi:10.1175/1520-0469(2002)059<2885:SMEONT>2.0.CO;2.

_, T. Takai, T. Nakamura, M. Yamamoto, and S. Fukao, 2010a: Simultaneous observations of thin humidity gradients in the lower troposphere with a Raman lidar and the very highfrequency middle- and upper-atmosphere radar. J. Atmos. Oceanic Technol., 27, 950-956, doi:10.1175/2010JTECHA1372.1. , and Coauthors, 2010b: Observations of Kelvin-Helmholtz instability at a cloud base with the middle and upper atmosphere (MU) and weather radars. J. Geophys. Res., 115, D19116, doi:10.1029/2009JD013519.

, T. Nakamura, M. K. Yamamoto, M. Yamamoto, and S. Fukao, 2010c: MU radar and lidar observations of clear-air turbulence underneath cirrus. Mon. Wea. Rev., 138, 438-452, doi:10.1175/2009MWR2927.1.

, R. Wilson, F. Dalaudier, H. Hashiguchi, N. Nishi, Y. Shibagaki, and T. Nakajo, 2014: Simultaneous observations of tropospheric turbulence from radiosondes using Thorpe analysis and the VHF MU radar. Radio Sci., 49, 1106-1123, doi:10.1002/2013RS005355.

Nath, D., M. Venkat Ratman, A. K. Patra, B. V. Krishna Murthy, and S. Vijaya Bhaskar Rao, 2010: Turbulence characteristics over tropical station Gadanki $\left(13.5^{\circ} \mathrm{N}, 79.2^{\circ} \mathrm{E}\right)$ estimated using high-resolution GPS radiosonde data. J. Geophys. Res., 115, D07102, doi:10.1029/2009JD012347.

Ozmidov, R. V., 1965: On the turbulent exchange in a stably stratified ocean. Izv. Akad. Nauk. SSSR, Atmos. Oceanic Phys., 1, 853-860.

Pavelin, E., J. A. Whiteway, and G. Vaughan, 2001: Observation of gravity wave generation and breaking in the lowermost stratosphere. J. Geophys. Res., 106, 5173-5179, doi:10.1029/ 2000JD900480.
Powell, S. W., and R. A. Houze Jr., 2013: The cloud population and onset of the Madden-Julian oscillation over the Indian Ocean during DYNAMO-AMIE. J. Geophys. Res. Atmos., 118, 11 979-11995, doi:10.1002/2013JD020421.

$\longrightarrow$, and - 2015: Evolution of precipitation and convective echo top heights observed by TRMM radar over the Indian Ocean during DYNAMO. J. Geophys. Res. Atmos., 120, 39063919, doi:10.1002/2014JD022934.

Redelsperger, J.-L., D. B. Parsons, and F. Guichard, 2002: Recovery processes and factors limiting cloud-top height following the arrival of a dry intrusion observed during TOGA COARE. J. Atmos. Sci., 59, 2438-2457, doi:10.1175/ 1520-0469(2002)059<2438:RPAFLC $>2.0 . C O ; 2$.

Reeder, M. J., N. Adams, and T. P. Lane, 1999: Radiosonde observations of partially trapped lee waves over Tasmania, Australia. J. Geophys. Res., 104, 16 719-16727, doi:10.1029/ 1999JD900038.

Rowe, A. K., and R. A. Houze Jr., 2014: Microphysical characteristics of MJO convection over the Indian Ocean during DYNAMO.J. Geophys. Res. Atmos., 119, 2543-2554, doi:10.1002/ 2013JD020799.

Ruppert, J. H., Jr., and R. H. Johnson, 2015: Diurnally modulated cumulus moistening in the pre-onset stage of the MaddenJulian oscillation during DYNAMO. J. Atmos. Sci., 72, 1622 1647, doi:10.1175/JAS-D-14-0218.1.

Sato K., M. Yamamori, S.-Y. Ogino, N. Takahashi, Y. Tomikawa, and T. Yamanouchi, 2003: A meridional scan of the stratospheric gravity wave field over the ocean in 2001 (MeSSO2001). J. Geophys. Res., 108, 4491, doi:10.1029/2002JD003219.

Schneider, A., M. Gerding, and F.-J. Lubken, 2015: Comparing turbulent parameters obtained from LITOS and radiosonde measurements. Atmos. Chem. Phys., 15, 2159-2166, doi:10.5194/ acp-15-2159-2015.

Sharman, R. D., S. B. Trier, T. P. Lane, and J. D. Doyle, 2012: Sources and dynamics of turbulence in the upper troposphere and lower stratosphere: A review. Geophys. Res. Lett., 39, L12803, doi:10.1029/2012GL051996.

_ L. L. B. Cornman, G. Meymaris, J. Pearson, and T. Farrar, 2014: Description and derived climatologies of automated in situ eddy-dissipation-rate report of atmospheric turbulence. J. Appl. Meteor. Climatol., 53, 1416-1432, doi:10.1175/ JAMC-D-13-0329.1.

Shimizu, A., and T. Tsuda, 1997: Characteristics of Kelvin waves and gravity waves observed with radiosondes over Indonesia. J. Geophys. Res., 102, 26159-26171, doi:10.1029/96JD03146.

Spencer, R. W., and W. D. Braswell, 1997: How dry is the tropical free troposphere? Implications for global warming theory. Bull. Amer. Meteor. Soc., 78, 1097-1106, doi:10.1175/ 1520-0477(1997)078<1097:HDITTF>2.0.CO;2.

Suzuki, J., M. Fujiwara, T. Nishizawa, R. Shirooka, K. Yoneyama, M. Katsumata, I. Matsui, and N. Sugimoto, 2013: The occurrence of cirrus clouds associated with eastward propagating equatorial $n=0$ inertio-gravity and Kelvin waves in November 2011 during the CINDY2011/DYNAMO campaign. J. Geophys. Res. Atmos., 118, 12 941-12 947, doi:10.1002/2013JD019960.

Takemi, T., 2015: Relationship between cumulus activity and environmental moisture during the CINDY2011/DYNAMO field experiment as revealed from convection-resolving simulations. J. Meteor. Soc. Japan, 93A, 41-58, doi:10.2151/ jmsj.2015-035.

Thorpe, S. A., 1977: Turbulence and mixing in a Scottish loch. Philos. Trans. Roy. Soc. London, A286, 125-181, doi:10.1098/ rsta.1977.0112. 
Tsuda, T., Y. Murayama, H. Wiryosumarto, S. Woro, B. Hajirono, and S. Kato, 1994a: Radiosonde observations of equatorial atmospheric dynamics over Indonesia: 1 . Equatorial waves and diurnal tides. J. Geophys. Res., 99, 10491-10505, doi:10.1029/94JD00355.

,,,,---- and,$- 1994 \mathrm{~b}$ : Radiosonde observations of equatorial atmospheric dynamics over Indonesia: 2. Characteristics of gravity waves. J. Geophys. Res., 99, $10507-$ 10516, doi:10.1029/94JD00354.

Vanneste, J., and P. H. Haynes, 2000: Intermittent mixing in strongly stratified fluid as a random walk. J. Fluid Mech., 411, 165-185, doi:10.1017/S0022112099008149.

Vialard, J., 2007: CIRENE 2007 cruise, RV Le Suroît. Systèmes d'Informations Scientifiques pour la Mer, doi:10.17600/7020010.

— , and Coauthors, 2009: CIRENE: Air-sea interactions in the Seychelles-Chagos thermocline ridge region. Bull. Amer. Meteor. Soc., 90, 45-61, doi:10.1175/2008BAMS2499.1.

Waite, M. L., and B. Khouider, 2010: The deepening of tropical convection by congestus preconditioning. J. Atmos. Sci., 67, 2601-2615, doi:10.1175/2010JAS3357.1.

Wheeler, M., and H. H. Hendon, 2004: An all-season Real-time Multivariate MJO index: Development of an index for monitoring and prediction. Mon. Wea. Rev., 132, 1917-1932, doi:10.1175/1520-0493(2004)132<1917:AARMMI>2.0.CO;2.

Wilson, R., 2004: Turbulent diffusivity in the free atmosphere inferred from MST radar measurements: A review. Ann. Geophys., 22, 3869-3887, doi:10.5194/angeo-22-3869-2004.

— - F. Dalaudier, and F. Bertin, 2005: Estimation of the turbulent fraction in the free atmosphere from MST radar measurements. J. Atmos. Oceanic Technol., 22, 1326-1339, doi:10.1175/ JTECH1783.1.

- , H. Luce, F. Dalaudier, and J. Lefrere, 2010: Turbulence patch identification in potential density or temperature profiles. J. Atmos. Oceanic Technol., 27, 977-993, doi:10.1175/ 2010JTECHA1357.1.

_- F. Dalaudier, and H. Luce, 2011: Can one detect small-scale turbulence from standard meteorological radiosondes? At mos. Meas. Tech., 4, 795-804, doi:10.5194/amt-4-795-2011.

- H. Luce, H. Hashiguchi, M. Shiotani, and F. Dalaudier, 2013: On the effect of moisture on the detection of tropospheric turbulence from in situ measurements. Atmos. Meas. Tech., 6, 697-702, doi:10.5194/amt-6-697-2013.

,,,-- N. Nishi, and Y. Yabuki, 2014: Energetics of persistent turbulent layers underneath mid-level clouds estimated from concurrent radar and radiosonde data. J. Atmos. Sol.-Terr. Phys., 118, 78-89, doi:10.1016/j.jastp.2014.01.005.

Woodman, R. F., and P. K. Rastogi, 1984: Evaluation of effective eddy diffusive coefficients using radar observations of turbulence in the stratosphere. Geophys. Res. Lett., 11, 243-246, doi:10.1029/GL011i003p00243.

Worthington, R. M., 2015: MST radar observations of turbulent altocumulus layers. Atmos. Sci. Lett., 16, 500-505, doi:10.1002/ asl588.

Xu, W., and S. Rutledge, 2014: Convective characteristics of the Madden-Julian oscillation over the central Indian Ocean observed by shipborne radar during DYNAMO. J. Atmos. Sci., 71, 2859-2877, doi:10.1175/JAS-D-13-0372.1.

- S. A. Rutledge, C. Schumacher, and M. Katsumata, 2015: Evolution, properties and spatial variability of MJO convection near and off the equator during DYNAMO. J. Atmos. Sci., 72, 4126-4147, doi:10.1175/JAS-D-15-0032.1.

Yoneyama, K., and Coauthors, 2008: MISMO field experiment in the equatorial Indian Ocean. Bull. Amer. Meteor. Soc., 89, 1889-1903, doi:10.1175/2008BAMS2519.1.

C. Zhang, and C. N. Long, 2013: Tracking pulses of the Madden-Julian oscillation. Bull. Amer. Meteor. Soc., 94, 18711891, doi:10.1175/BAMS-D-12-00157.1.

Zermeño-Díaz, D. M., C. Zhang, P. Kollias, and H. Kalesse, 2015: The role of shallow cloud moistening in MJO and non-MJO convective events over the ARM Manus site. J. Atmos. Sci., 72, 4797-4820, doi:10.1175/JAS-D-14-0322.1.

Zhang, J., H. Chen, Z. Li, X. Fan, L. Peng, Y. Yu, and M. Cribb, 2010: Analysis of cloud layer structure in Shouxian, China using RS92 radiosonde aided by $95-\mathrm{GHz}$ cloud radar. J. Geophys. Res., 115, D00K30, doi:10.1029/2010JD014030.

Zuluaga, M. D., and R. A. Houze Jr., 2013: Evolution of the population of precipitating convective systems over the equatorial Indian Ocean in active phases of the MaddenJulian oscillation. J. Atmos. Sci., 70, 2713-2725, doi:10.1175/ JAS-D-12-0311.1. 